San Jose State University

SJSU ScholarWorks

Master's Projects

Master's Theses and Graduate Research

Fall 2015

\title{
An Investigation of the Effectiveness of Persuasive Mechanics in Social Network Registrations
}

Nathan Cook

San Jose State University

Follow this and additional works at: https://scholarworks.sjsu.edu/etd_projects

\section{Recommended Citation}

Cook, Nathan, "An Investigation of the Effectiveness of Persuasive Mechanics in Social Network

Registrations" (2015). Master's Projects. 1035.

DOI: https://doi.org/10.31979/etd.acbf-grm8

https://scholarworks.sjsu.edu/etd_projects/1035

This Master's Project is brought to you for free and open access by the Master's Theses and Graduate Research at SJSU ScholarWorks. It has been accepted for inclusion in Master's Projects by an authorized administrator of SJSU ScholarWorks. For more information, please contact scholarworks@sjsu.edu. 
An Investigation of the Effectiveness of Persuasive

Mechanics in Social Network Registrations

Nathan Cook

San Jose State University 


\begin{abstract}
This study involved 40 participants from the community of varying ages and genders filling out various versions of a social network registration that utilized no persuasive mechanics, a praise persuasive mechanic, a social-pressure persuasive mechanic, and both mechanics combined in an effort to determine the effectiveness of each by measuring the amount of data supplied during registration, as well as self-reported scores on a persuasiveness scale. Attitudes towards risk as well as gender were factors also considered. The results were not statistically significant with the exception of the final, self-reported, most-persuasive design. Participants felt overall that nomechanics was the most persuasive. Possible effects, causes, and implications for future research are discussed.
\end{abstract}


Running head: EFFECTIVENESS OF PERSUASSIVE MECHANICS

\section{ACKNOWLEDGEMENTS}

A special thanks goes out to my professor and advisor, Daniel Rosenberg for his continual advice and help in shaping this study. 


\section{TABLE OF CONTENTS}

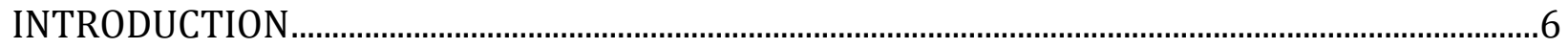

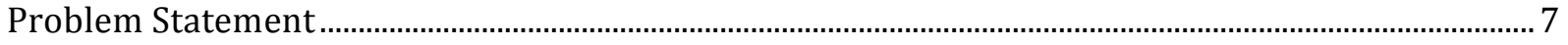

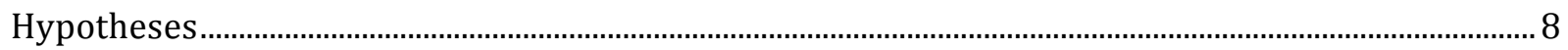

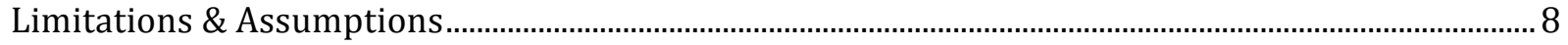

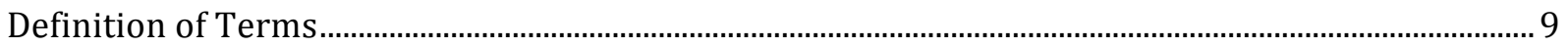

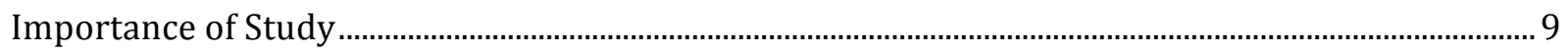

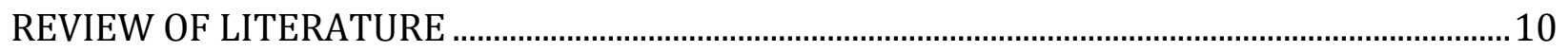

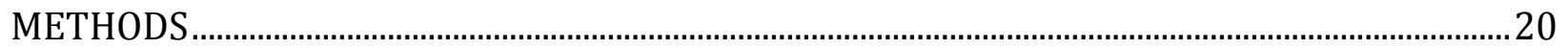

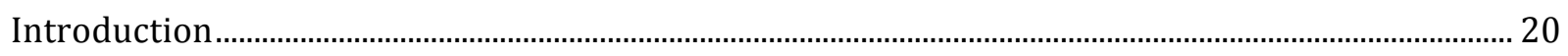

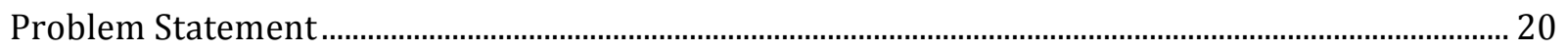

Design (Independent \& Dependent Factors, and Groups)............................................................... 21

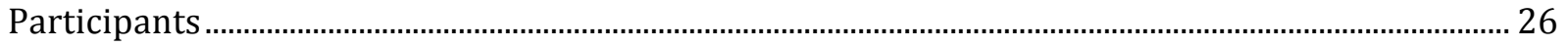

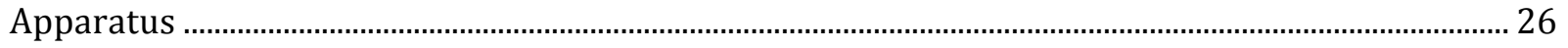

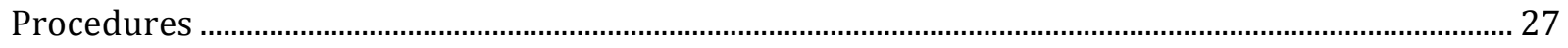

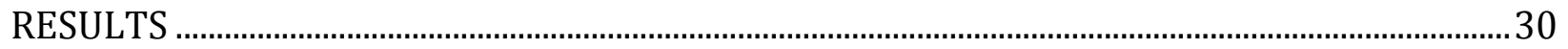

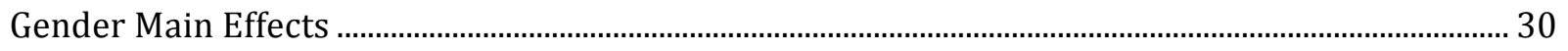

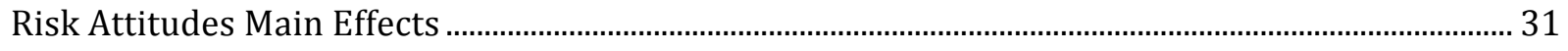

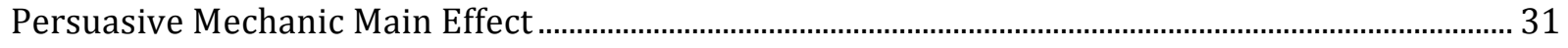

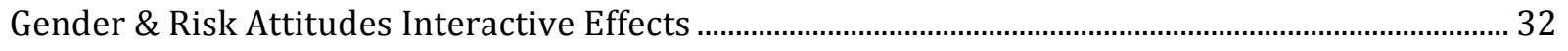

Persuasive Mechanic \& Gender Interactive Effect …............................................................................... 33

Persuasive Mechanic \& Risk Attitude Interactive Effect ........................................................................... 34

Persuasive Mechanic, Risk Attitude, \& Gender Interactive Effect......................................................... 35

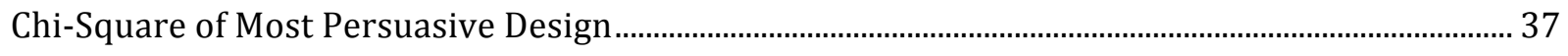




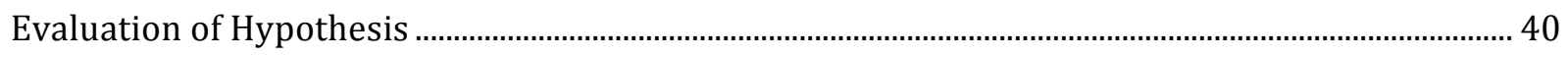

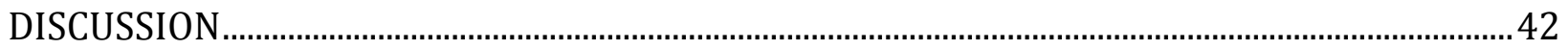

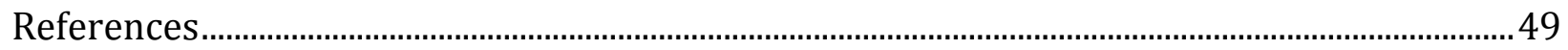

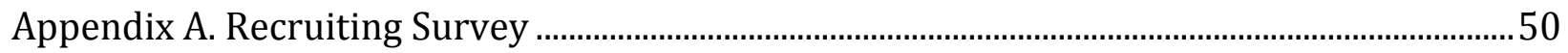

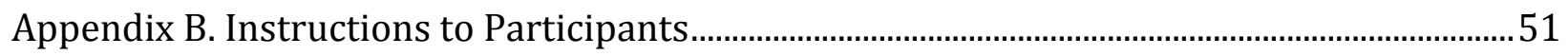

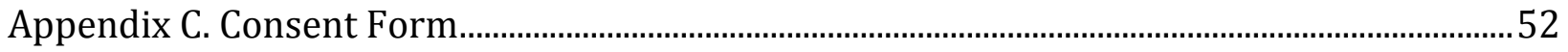

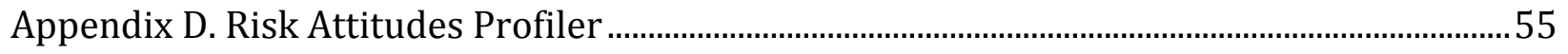

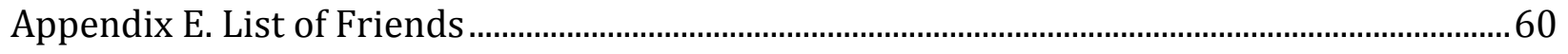

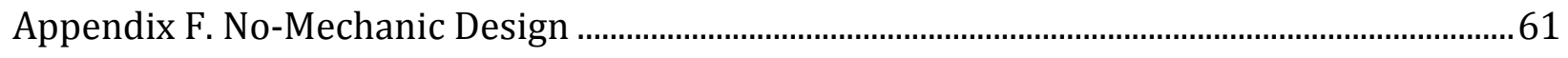

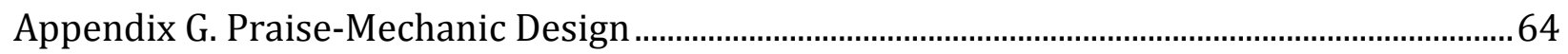

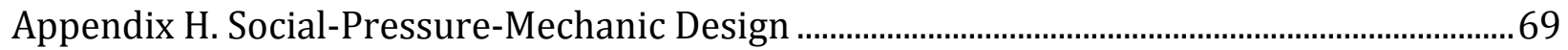

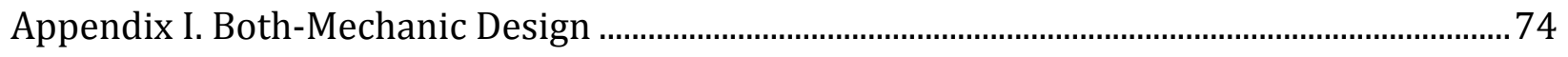

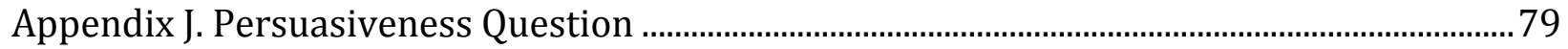

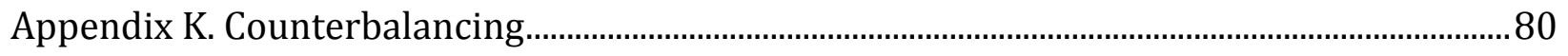

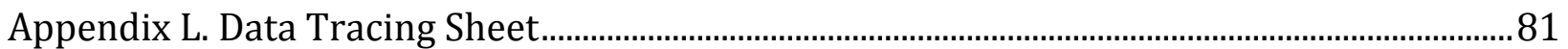




\section{Chapter 1}

\section{INTRODUCTION}

In the last twenty years, the Internet has revolutionized our world. From humble beginnings, the web has become a repository for all the world's knowledge, including knowledge about ourselves. This growth has led to some complexities. More and more websites and services require users to login in order to personalize the user experience. Originally, creating accounts and logins required very little information from the user. Now, in order to personalize the user experience, websites and their registrations require more data than ever before.

In addition to collecting information to provide customized experiences, collecting information about users has also become profitable to the corporations who manage these websites and services. In the last decade, for example, social networking has grown exponentially. With millions of users, people often question how free-to-use sites like Facebook, Google+, and Twitter make money. The answer is targeted advertising.

Their ability to precisely sell targeted ad space is completely dependent on their ability to collect personal data about their users however, such as location, demographic information, interests, favorite hobbies, music, movies, and books, etc. The ability to collect as much information as possible aids them in their mission to sell precisely-targeted advertisements.

Each business goes about the task of user-data collection in slightly different ways. Though many of these sites continually collect information about their users, this process begins with the registration. The ability to collect as much of this information as soon as possible (in the initial registration) is immensely profitable for these corporations. 
In an age with growing concern for privacy however, how do these companies persuade their users to provide personal information about themselves? Such a question leads to a discussion in persuasive user experience design (also known as the field of Captology).

This study was aimed to determine the effectiveness of one or a combination of two different persuasive techniques in persuading users to provide more data about themselves in website registrations than if no persuasive techniques are used at all. Other factors that may influence the effectiveness of various persuasive mechanics, such as gender, and willingness to engage in risk-taking behavior were also considered. Comparing the registration completions rates, the amount of data collected by registration designs utilizing different persuasive mechanics, as well as subjective quantitative and qualitative data from users about the persuasiveness of each design was hoped to give greater insight into the effectiveness of various persuasive techniques.

\section{Problem Statement}

The purpose of this study was to determine:

1) How gender, risk-taking attitudes, different persuasive techniques, and combinations of these have an affect on social-network registration completion rates.

2) How gender, risk-taking attitudes, different persuasive techniques, and combinations of these have an affect on the amount of data provided by users in social-network registrations.

3) How gender, risk-taking attitudes, different persuasive techniques, and combinations of these have an affect on the perceived persuasiveness of social-network registrations. 


\section{Hypotheses}

The following hypotheses were made for the purpose of the study:

1) A combination of persuasive mechanics would be more successful than single mechanics or the use of no mechanics in persuading participants to complete a registration.

2) A combination of persuasive mechanics would be more successful than single mechanics or the use of no mechanics in persuading participants to provide more information about themselves during registration.

3) A combination of persuasive mechanics would be perceived by participants as being more persuasive than single mechanics or the use of no mechanics during registration.

4) Different groups of people (gender, risk-taking attitudes, and their various combinations) would be more persuaded by different persuasive mechanics to complete registration and provide more information than other groups.

5) Different groups of people (gender, risk-taking attitudes, and their various combinations) would perceive different persuasive mechanics as being more persuasive than other groups.

\section{Limitations \& Assumptions}

Due to the number of registration designs each participant could have experienced, fatigue and priming effects may have been present.

Because participants knew that the site was fake, their behavior might have been altered. Namely, participants may have been willing to provide more information than they would have normally. 
Additionally, participants may not have viewed website registration as much of a risk, especially younger participants who have been exposed to website registration and personal data collection for the majority of their lives. Even risk-adverse participants may not have viewed this as a risky behavior.

\section{Definition of Terms}

Data points: Each text entry, check box, and data import in the registration, after the first required page, was considered an individual data point.

\section{Importance of Study}

Many online businesses survive based on their ability to sell targeted-advertisements. As such, being able to collect as much information about users as quickly as possible to target them is crucial to the success of the company. Knowing which persuasive techniques will persuade users to supply the most information during initial registration will help them achieve this goal. 


\section{Chapter 2}

\section{REVIEW OF LITERATURE}

A discussion of effectiveness of systems to convince people to supply information about themselves lends itself to a discussion in persuasion. Before discussing how persuasion takes place, a definition of persuasion is in order. As defined by Fogg (1998), persuasion is "an attempt to shape, reinforce, or change behaviors, feelings, or thoughts about an issue, object, or action." (pg. 225)

The art or science of persuasion has been a topic of human interest for centuries. Even as early as 350 B.C. Aristotle discussed three primary categories of persuasive techniques. The first technique he identified was to rely on the speaker's credibility. Establishing credibility or convincing others of one's credibility led to more persuasive arguments. Secondly, tapping into and utilizing the emotions of the listeners was useful in persuasion. Lastly, he noted that an appeal to logic and rational thinking was also a successful persuasion technique. (Aristotle)

Since the dawn of psychology as a science and the study thereof, scientists have studied the art of persuasion and the techniques used to successfully persuade. In recent decades, we have replaced many human-to-human tasks with human-computer tasks, many of which involve persuasive interactions - for example, shopping once meant going to a store and speaking with a sales clerk who could use persuasive techniques to secure a sale. Now, many shopping experiences take place in the comfort of our own homes via the Internet. As such, business, in particular, began to question how they could be more persuasive through technology.

An early paper in the field of computer as persuasive technology conducted by Marshall and Maguire (1971) noted prior research in social conformity and human tendency to conform to 
social opinions about perceived objects in disregard to our own perceptions. Furthermore, they detailed their interest in knowing if computers can exhibit a similar social pressure and an experiment they conducted to study that very idea. Their results showed that social conformity did in fact exist with human-computer interactions. In other words, humans had a tendency to conform with computer "opinions" just like they tend to do with the opinions of other human beings.

As computers became more prolific in our lives, the question of how computers could persuade humans became of greater concern. Early studies into if and how computers could persuade by pioneers such as Fogg, Moon, and Nass (Fogg \& Nass 1997a; Fogg \& Nass 1997b; Nass, Fogg, \& Moon 1996;) showed that computers could very clearly persuade people using a variety of techniques including exhibiting similar personality traits, praise, and reciprocation.

As the field began to emerge, a group of scientists interested in the field met at the CHI conference in 1997, decided to name the field "captology," which stood for Computers As Persuasive Technologies. In an early paper by Fogg (1998) a framework of how computers could persuade was proposed. He suggested that computers could persuade in one or more of three basic ways: 1) as a tool, computers can persuade behaviors by reducing barriers for certain behaviors thereby increasing their likelihood, increasing self-efficacy by making behaviors seem achievable, 2) providing information that allows informed decisions, and 3) computers could be persuasive as a medium and as a social actor.

Later work by Fogg goes into greater detail about each of these categories of persuasion. He explains that computers can be social actors acting like a human to create relationships with users and this in turn increases their capacity to persuade in a number of ways (2003). In his 
book, he details five types of social cues computers can use to be persuasive. The first, physical details that by taking on physical traits of human being, such as using human-like characters in software and/or being attractive in nature in their own right opens doors for persuasion.

Second, Fogg (2003) details that by using psychological cues such as similarity, computers can also be more persuasive. This principal simply states that people who we think are similar to us in personality, preferences, or other attributes are more persuasive. If computers could emulate personality traits that we deem similar to our own, they too would then be more persuasive. In an experiment conducted by Nass, Moon, Fogg, Reeves, and Dryer (1995), they conclusively showed that computers who took on dominant or submissive personalities were more persuasive when people with similar personalities used these respectively. In another study a year later, Nass, Fogg and Moon (1996) demonstrate that by merely referring to a computer as a teammate, also increases its ability to persuade, which they speculated arised from the same similarity principal. Simply put, being on the same team, the computer automatically becomes more trustworthy and therefore its ability to persuade increases. Another psychological cue is to tap into our basic need to feel like we "belong" (Baumeister \& Leary, 1995). As demonstrated by Marshall \& Maguire (1971), as previously discussed, our need to socially conform can also be utilized by computers to persuade.

The third type of social cue computers can use to persuade, as discussed by Fogg (2003) is through the use of language. As demonstrated by Fogg \& Nash (1997b), flattery and praise by computers can also be utilized to persuade.

The fourth social cue (Fogg, 2003), social dynamics, details that by following social norms and customs, computers also become more persuasive. For example, the well-documented 
norm of reciprocity states that when we receive a favor, we feel obligated to return it (Gouldner, 1960). As detailed by Fogg \& Nass (1997a), human beings also follow this rule with computers when they feel the computer has done them a favor, they feel obligated to return the favor, and as such, this technique can be used to persuade as well.

The fifth, and final social cue that Fogg (2003) outlines as a means for computer persuasion, is the role of social roles. In society, certain roles are more persuasive, such as teachers, counselors, or trainers. We are often more easily persuaded by authority figures, because we trust in their authority (much like Aristotle believed). If computers take on personas of such roles, they too can persuade in a similar fashion, by posing themselves as experts of a particular subject.

Later work by Oinas-Kukkonen \& Harjumaa (2009) noted that Fogg's framework lacked a certain level of applicability, which could be utilized in the creation and evaluation of persuasive systems. They noted the need to lie out specific techniques and mechanisms that can be utilized by computers to persuade. They further expanded on the idea that computers can be a tool are persuasion by adding that they are only persuasive in so much as they are useful, efficient, and easy to use, indicating that standard usability metrics, such as low error rates, and speed of task completion also contribute to the persuasiveness of a computer. One could theorize this is built upon the norm of reciprocity however - by helping us be more productive and efficient, we feel the need to return the favor.

Nevertheless, their framework outlines four basic categories of techniques and principals that can be utilized in persuasive design. These are: 1) primary task support, 2) dialogue support, 3) systems credibility support, and 4) social support. Many principals within these categories are 
used by major social networking sites as part of their efforts to continually collection information about their users. For example, tunneling is a technique of using a system to guide users through a step-by-step process. This is used in initial registrations for social networking sites to guide people through the setup process of providing necessary data, with the goal of connecting people with information about their friends and interests. Once information is collected, these systems personalize information to continually persuade users to continue to use the system. Personalization is a technique they noted as having a great effect on persuasion. In fact, this is the primary technique utilized by these companies to sell ads and be profitable. Often, these websites will tailor their experience (another technique noted by Oinas-Kukkonen \& Harjumaa). They do this by offering new suggested content that may be of interest to the users (groups, pages, etc.) based on previously provided information. Furthermore, normative influence (social pressure) is another technique often utilized by social networking in forms such as " $\mathrm{x}$ number of users liked this." This capitalizes once again on our need to belong and for similarity. Social learning is often used as well. This technique persuades people to engage in a behavior (such as sharing) if they see others engaging in that behavior. These sites post shared content by others to a user's news feed for them to see. Many other principles they outlined are also used, all to persuade users to engage in certain behaviors such as sharing, liking, following, commenting, etc. All with the end goal of continued use and continued data collection.

In looking at persuasive techniques utilized by applications on Facebook, Weiksner, Fogg, \& Liu (2008) categorized the persuasive techniques they used to attract users into six patterns. The first of these, provoke and retaliate, allow users to "poke" or "nudge" someone to suggest they use a particular application. They noted that this capitalizes on the norm of reciprocity. The second, Expression, allows users to create artifacts, like drawings and capitalizes on the human 
need to express oneself. The third, reveal and compare, allows users to take actions on other users, like provoke and retaliate, but on groups of people. This utilizes human need to belong as a persuasive technique. The fourth, group exchange, allows users to create and share objects collectively, an activity native to Facebook. The authors noted that this capitalizes on the human need to manage external impression (Leary \& Kowalski, 1990). The fifth pattern, competition, allows users to compete in games for top ranking. This capitalizes on human desire for cognition and recognition. The last and final pattern, deception is a pattern of placing ads that look like a part of the application to trick people into clicking on them.

All in all, we can see that persuasive techniques utilized by social networking sites will rely primarily on the emotional component of persuasion as discussed by Aristotle, including our need for belonging, similarity, praise, reciprocity, cooperation, and expression amongst others. Additionally, as tools, systems can be persuasive if they're efficient, valuable, and easy to use.

Many of these studies have established that computers can effectively persuade human beings using a variety of techniques, but few, if any have compared the effectiveness of different techniques in applied settings, such as social networking sites.

Social networking sites already utilize a number of these persuasive techniques to engage users in providing further information about their interests, which is vital to their business models. Many of these come in the form of suggestions and other social dynamics. Statements like "x number of friends like this" for example, encourages users to "like" the item as well by utilizing suggestion and social pressures such as conformity. But just how effective are they? Furthermore, most of these techniques are not utilized during the initial registration for such sites, which could potentially be beneficial in increasing completion rates for registrations as well as 
increasing the amount of information users provide during the initial onboarding experience, which again, would be beneficial and profitable.

Generally speaking, some of the most popular social networking sites (Facebook, Google+, and Twitter) employ a 3 or 4 step registration. The first step generally includes the collection of the person's name, email address, gender, and date of birth (see Figure 1). The $2^{\text {nd }}$ step allows a person to upload contact lists from various email clients in an attempt to find friends already on the social networking site (see Figure 2). The $3^{\text {rd }}$ step collects other information such as hometown, current location, school attendance and employer in an attempt to find further friends (see Figure 3). The last step, employed notably by Google+ and Twitter, but not Facebook is to collect information about topics of interest to people (see Figure 4).

After a careful analysis of the various persuasive mechanics discussed in the body of literature by Fogg, Oinas-Kukkonen, Harjumaa, and others, these social networking sites only utilize two persuasive techniques in their registrations, namely a call to logic in an attempt to increase trustworthiness, and tunneling (see Figure 1). In general, each call for information includes a reason for the information and how it will be used. These steps could incorporate other persuasive designs however in an effort to increase registration completion rates, and to collect further information (as much of the information requested in these registrations is optional). 


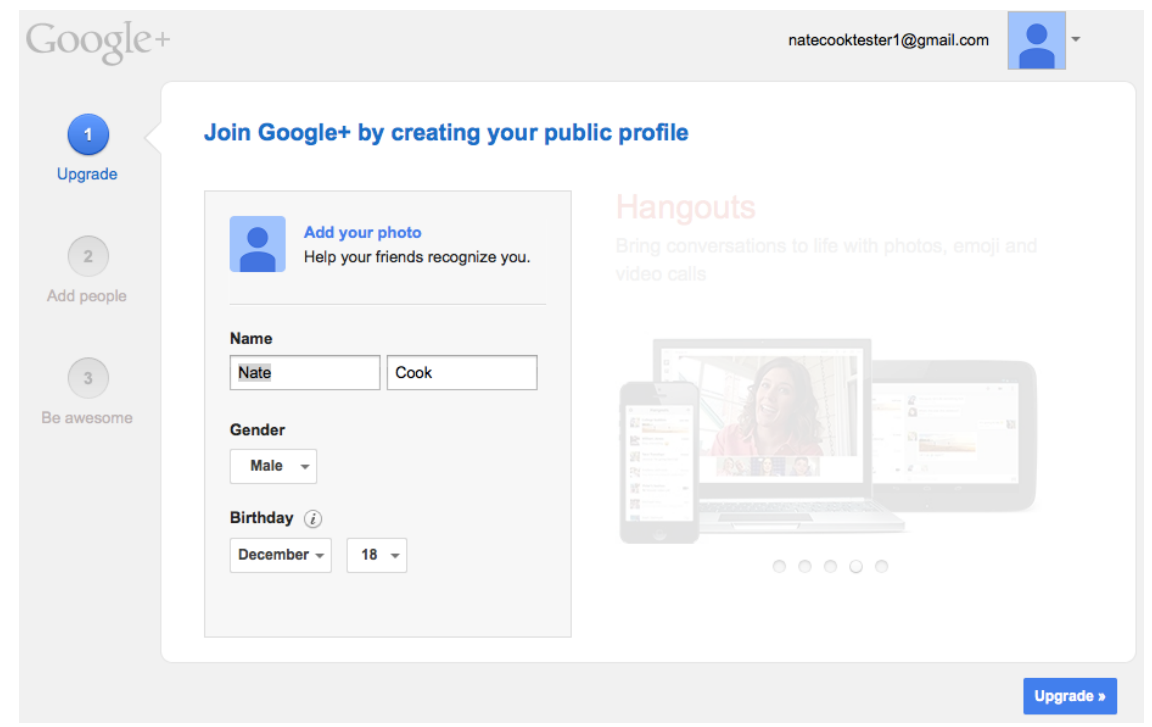

Figure 1. Google+'s registration step 1 asks for name, gender and birth (having already been signed into Google, it did not ask for email). Text like "help your friends recognize you" explain the purpose behind uploading a picture, appealing to a sense of logic which can be persuasive.

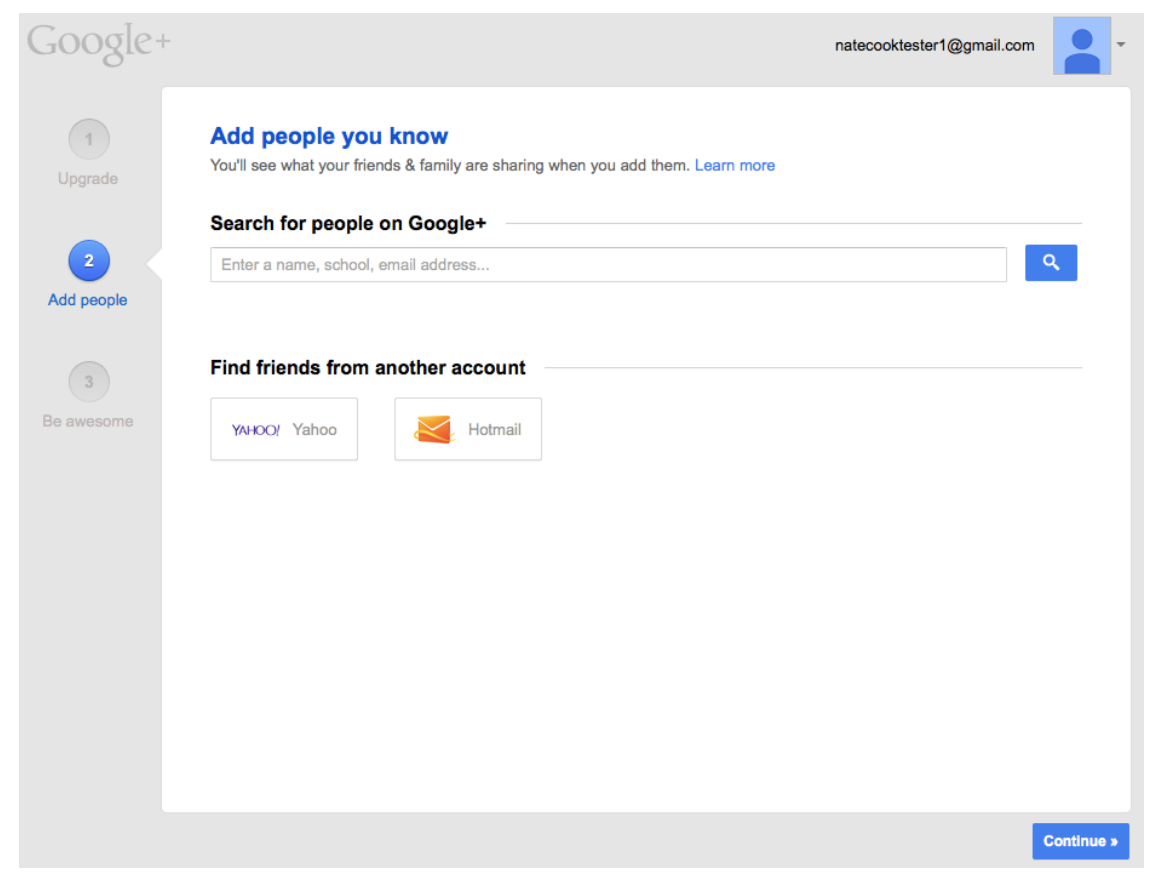

Figure 2. Google+ registration step 2 allows users to search for friends and import contacts from other email clients to find friends. 


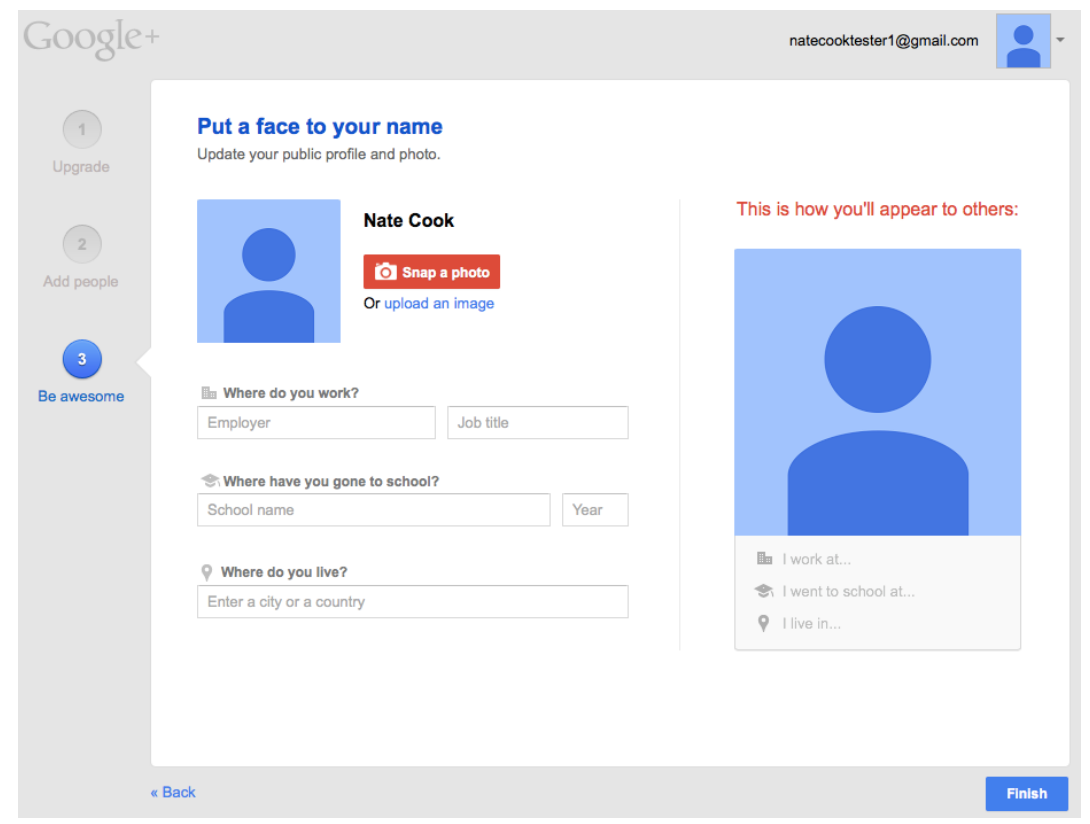

Figure 3. Google+ registration step 3 allows the user to supply their employment and schooling info as well as a picture and city of residence.

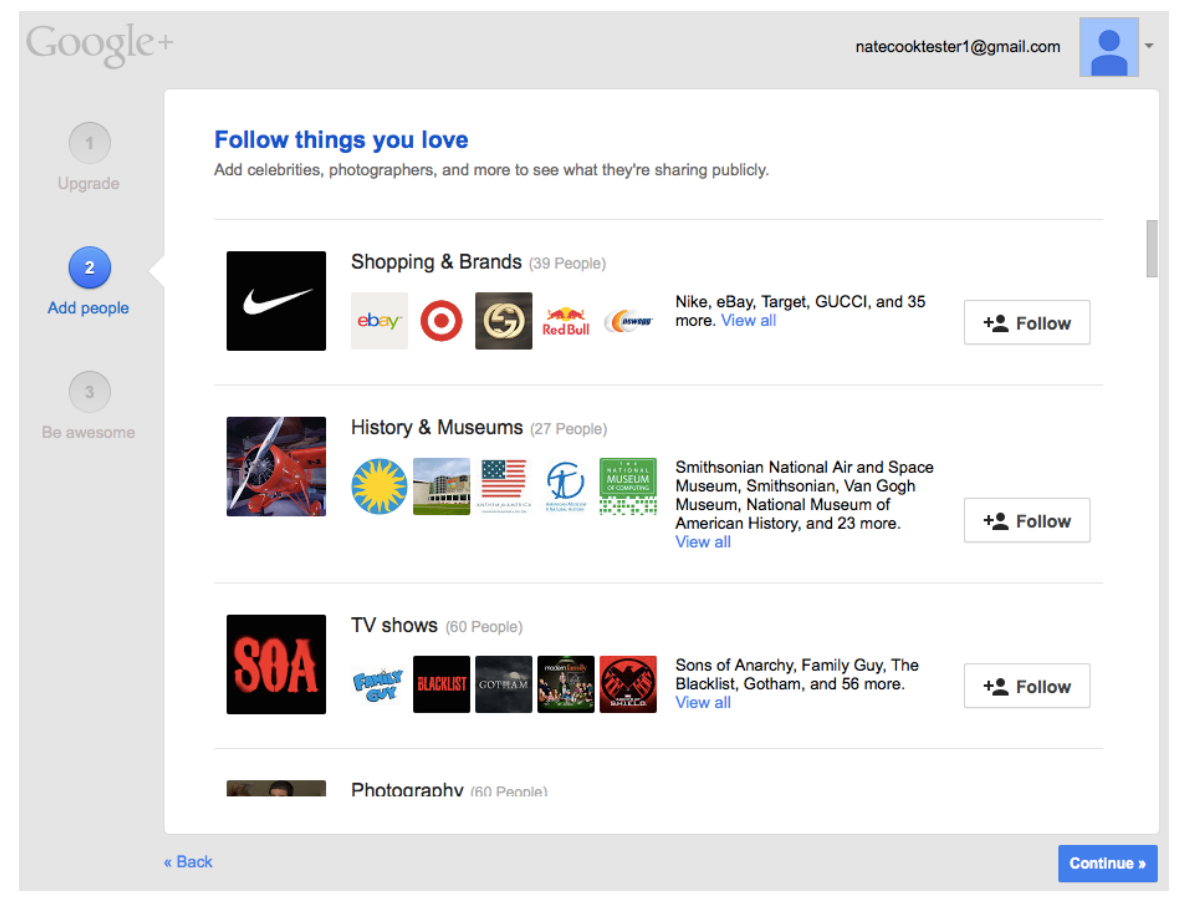

Figure 4. Google+ registration step 4 allows people to select topics and businesses of interest. 
Based on this analysis, there are two persuasive techniques that could logically be utilized in these registrations that currently are not. The use of praise after each completed step could be easily implemented in the registrations. Secondly, utilizing the power of social pressures by offering suggested topics of interest based on the topics of interest of friends or showing the percent of people who complete various registration steps could be beneficially persuasive. As such, it is of interest to see how utilizing these persuasive techniques might influence the registration completion rates and the amount of information users provide. 


\section{Chapter 3}

\section{METHODS}

\section{Introduction}

This study aimed to determine which of two persuasive mechanics is most effective in persuading users to supply data during registration and if combining these mechanics in a single registration has an even greater persuasive effect. Comparing the amount of data collected, completions rates, and self-reported persuasiveness scores to the persuasive mechanic used, gender, and risk attitude, as well as qualitative data from users about the persuasiveness of each design was hoped to provide greater insight into the effectiveness of various persuasive techniques for different groups of people.

\section{Problem Statement}

The purpose of this study was to determine if:

1) A combination of persuasive mechanics would be more successful than single mechanics or the use of no mechanics in persuading participants to complete a registration.

2) A combination of persuasive mechanics would be more successful than single mechanics or the use of no mechanics in persuading participants to provide more information about themselves during registration.

3) A combination of persuasive mechanics would be perceived by participants as being more persuasive than single mechanics or the use of no mechanics during registration. 
4) Different groups of people (gender and risk-taking attitudes) would be more persuaded by different persuasive mechanics to complete registration and provide more information than other groups.

5) Different groups of people (gender and risk-taking attitudes) would perceive different persuasive mechanics as being more persuasive than other groups.

\section{Design (Independent \& Dependent Factors, and Groups)}

The two different persuasive design techniques and their combination were utilized and tested to determine their effects on the amount of data participants were willing to provide (Appendix F-I for full designs). The first of these used praise (see figure 5) after every submission of data. The second utilized social pressure (see figure 6), by suggesting topics of interests based on a person's friends and providing the percent of users who have completed each step. These two, and their combination (see figure 7), constituted three different states of the manipulated independent variable (persuasive technique) for this experiment. A design not incorporating any of these persuasive techniques was used as a control (see figure 8).

Additionally, two other non-manipulated independent variables were investigated: gender, and risk-taking attitudes. 


\begin{tabular}{|c|c|c|c|c|}
\hline \multicolumn{5}{|c|}{ Your friends are very interesting people! } \\
\hline & \multicolumn{4}{|c|}{$\begin{array}{l}\text { Tell us which of the following topics you are interested in and } \\
\text { we'll show you related content. }\end{array}$} \\
\hline Travel & Sports & & Music & $\square$ News \\
\hline TV Shows & Nature & & Movies & Games \\
\hline Education & Parenting \& Kids & & Business \& Finance & Shopping \\
\hline Photography & Art \& Design & & Politics & Fashion \& Beauty \\
\hline DIY \& Crafts & Science & & Food \& Drink & Auto \\
\hline$\square$ Spirituality & Literature & & Health \& Fitness & $\square$ Weddings \\
\hline Technology & History \& Museums & & Home \& Garden & Animals \\
\hline & & Continue & & \\
\hline & & Skip this step & & \\
\hline
\end{tabular}

Figure 5. Registration utilizing a praise persuasive mechanic.

\section{Follow Interests}

Tell us which of the following topics you are interested in and we'll show you related content.

$\mathbf{9 5 \%}$ of your friends follow at least 3 interests

Travel
Julie Spoon, Jeremy Knife,
\& 2 more follow
TV Shows
Katrina Glass \& Julie Spoon
follow
Education
Photography
DIY \& Crafts
Spirituality
Technology

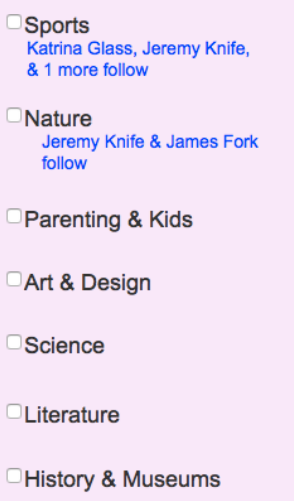

$\square$ Music James Fork, Julie Spoon \& 1 more follow

Movies Katrina Glass \& James Fork follow

Business \& Finance

Politics

Food \& Drink

Health \& Fitness

Home \& Garden

News

Jeremy Knife, James Fork \& 1 more follow

Games Julie Spoon \& Jeremy Knife follow

Shopping

Fashion \& Beauty

Auto

Weddings

Animals

\section{Continue}

Skip this step

Figure 6. Registration utilizing a social pressure persuasive mechanic. 
Your friends are very interesting people!

\section{Follow Interests}

Tell us which of the following topics you are interested in and we'll show you related content.

$95 \%$ of your friends follow at least 3 interests

Travel
Julie Spoon, Jeremy Knife,
\& 2 more follow
TV Shows
Katrina Glass \& Julie Spoon
follow
Education
Photography
DIY \& Crafts
Spirituality
Technology

Sports
Katrina Glass, Jeremy Knife,
\& 1 more follow
Nature
Joremy Knife \& James Fork
follow
Parenting \& Kids
Art \& Design
Science
Literature
History \& Museums

$\square$ Music

James Fork, Julie Spoon

\& 1 more follow

Movies

Katrina Glass \& James Fork

follow

Business \& Finance

Politics

Food \& Drink

Health \& Fitness

Home \& Garden

$\square$ News

Jeremy Knife, James Fork

\& 1 more follow

$\square$ Games

Julie Spoon \& Jeremy Knife

follow

Shopping

Fashion \& Beauty

Auto

Weddings

Animals

Continue

Skip this step

Figure 7. Registration utilizing both persuasive mechanics.

\section{Follow Interests}

Tell us which of the following topics you are interested in and we'll show you related content.

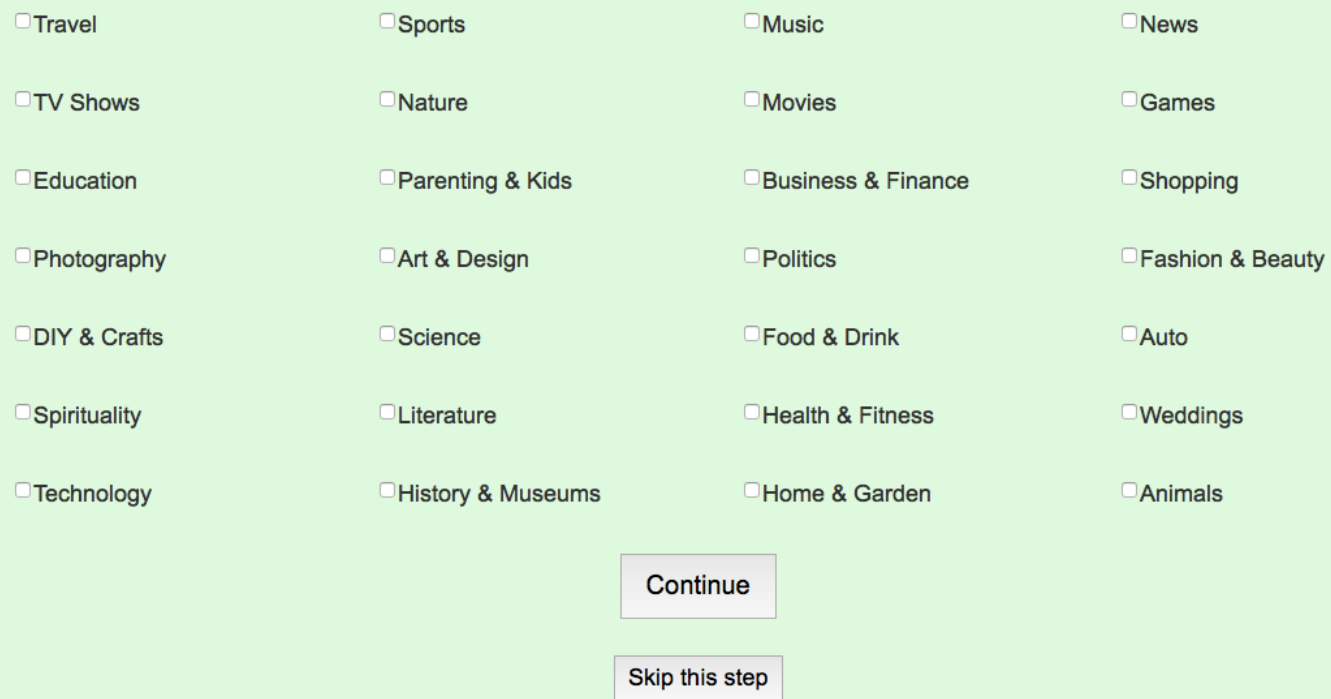

Figure 8. Registration utilizing no persuasive mechanics. 
Participants were asked to complete the four different registrations utilizing no persuasive techniques, each persuasive technique individually, and the combination of these techniques in a within-subjects design, while gender and risk-taking attitudes incorporated a between-subjects factorial design (see table 1). The completion rates of each registration, the number of datapoints each participant provided during each registration, as well as their subjective ratings of persuasiveness on a 7-point Likert scale (Appendix J) severed as the dependent variables for this study. The order in which participants filled-out the registrations were counterbalanced to account for priming and fatigue effects. 
Table 1

Study Design

\begin{tabular}{|c|c|c|c|c|c|}
\hline & \multicolumn{4}{|c|}{$\begin{array}{l}\text { Persuasive Mechanic Utilized in Registration Design } \\
\text { (all four were experience by all participants) }\end{array}$} \\
\hline & & None & Praise & Social Pressure & Both \\
\hline \multirow{3}{*}{$\frac{0}{\pi}$} & $\begin{array}{l}\text { Risk- } \\
\text { Adverse }\end{array}$ & $\begin{array}{l}\text { - Registration } \\
\text { Completion } \\
\text { - Number of data } \\
\text { points provided } \\
\text { - Self-reported } \\
\text { persuasiveness } \\
\end{array}$ & $\begin{array}{l}\text { - Registration } \\
\text { Completion } \\
\text { - Number of data } \\
\text { points provided } \\
\text { Self-reported } \\
\text { persuasiveness } \\
\end{array}$ & $\begin{array}{l}\text { - Registration } \\
\text { Completion } \\
\text { - Number of data } \\
\text { points provided } \\
\text { Self-reported } \\
\text { persuasiveness } \\
\end{array}$ & $\begin{array}{l}\text { - Registration } \\
\text { Completion } \\
\text { - Number of data } \\
\text { points provided } \\
\text { Self-reported } \\
\text { persuasiveness } \\
\end{array}$ \\
\hline & $\begin{array}{l}\text { Moderate } \\
\text { Risk } \\
\text { Takers }\end{array}$ & $\begin{array}{l}\text { - Registration } \\
\text { Completion } \\
\text { - Number of data } \\
\text { points provided } \\
\text { - Self-reported } \\
\text { persuasiveness }\end{array}$ & $\begin{array}{l}\text { - Registration } \\
\text { Completion } \\
\text { - Number of data } \\
\text { points provided } \\
\text { - Self-reported } \\
\text { persuasiveness }\end{array}$ & $\begin{array}{l}\text { - Registration } \\
\text { Completion } \\
\text { - Number of data } \\
\text { points provided } \\
\text { - Self-reported } \\
\text { persuasiveness } \\
\end{array}$ & $\begin{array}{l}\text { - Registration } \\
\text { Completion } \\
\text { - Number of data } \\
\text { points provided } \\
\text { - Self-reported } \\
\text { persuasiveness }\end{array}$ \\
\hline & $\begin{array}{l}\text { Risk- } \\
\text { Seeking }\end{array}$ & $\begin{array}{l}\text { - Registration } \\
\text { Completion } \\
\text { - Number of data } \\
\text { points provided } \\
\text { - Self-reported } \\
\text { persuasiveness }\end{array}$ & $\begin{array}{l}\text { - Registration } \\
\text { Completion } \\
\text { - Number of data } \\
\text { points provided } \\
\text { - Self-reported } \\
\text { persuasiveness }\end{array}$ & $\begin{array}{l}\text { - Registration } \\
\text { Completion } \\
\text { - Number of data } \\
\text { points provided } \\
\text { - Self-reported } \\
\text { persuasiveness }\end{array}$ & $\begin{array}{l}\text { - Registration } \\
\text { Completion } \\
\text { - Number of data } \\
\text { points provided } \\
\text { - Self-reported } \\
\text { persuasiveness }\end{array}$ \\
\hline \multirow{3}{*}{ 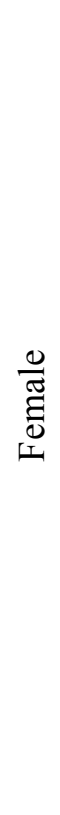 } & $\begin{array}{l}\text { Risk- } \\
\text { Adverse }\end{array}$ & $\begin{array}{l}\text { - Registration } \\
\text { Completion } \\
\text { - Number of data } \\
\text { points provided } \\
\text { - Self-reported } \\
\text { persuasiveness } \\
\end{array}$ & $\begin{array}{l}\text { - Registration } \\
\text { Completion } \\
\text { - Number of data } \\
\text { points provided } \\
\text { - Self-reported } \\
\text { persuasiveness }\end{array}$ & $\begin{array}{l}\text { - Registration } \\
\text { Completion } \\
\text { - Number of data } \\
\text { points provided } \\
\text { - Self-reported } \\
\text { persuasiveness } \\
\end{array}$ & $\begin{array}{l}\text { - Registration } \\
\text { Completion } \\
\text { - Number of data } \\
\text { points provided } \\
\text { - Self-reported } \\
\text { persuasiveness }\end{array}$ \\
\hline & $\begin{array}{l}\text { Moderate } \\
\text { Risk } \\
\text { Takers }\end{array}$ & $\begin{array}{l}\text { - Registration } \\
\text { Completion } \\
\text { - Number of data } \\
\text { points provided } \\
\text { - Self-reported } \\
\text { persuasiveness }\end{array}$ & $\begin{array}{l}\text { - Registration } \\
\text { Completion } \\
\text { - Number of data } \\
\text { points provided } \\
\text { - Self-reported } \\
\text { persuasiveness }\end{array}$ & $\begin{array}{l}\text { - Registration } \\
\text { Completion } \\
\text { - Number of data } \\
\text { points provided } \\
\text { - Self-reported } \\
\text { persuasiveness }\end{array}$ & $\begin{array}{l}\text { - Registration } \\
\text { Completion } \\
\text { - Number of data } \\
\text { points provided } \\
\text { - Self-reported } \\
\text { persuasiveness }\end{array}$ \\
\hline & $\begin{array}{l}\text { Risk- } \\
\text { Seeking }\end{array}$ & $\begin{array}{l}\text { - Registration } \\
\text { Completion } \\
\text { - Number of data } \\
\text { points provided } \\
\text { - Self-reported } \\
\text { persuasiveness }\end{array}$ & $\begin{array}{l}\text { - Registration } \\
\text { Completion } \\
\text { - Number of data } \\
\text { points provided } \\
\text { - Self-reported } \\
\text { persuasiveness }\end{array}$ & $\begin{array}{l}\text { - Registration } \\
\text { Completion } \\
\text { - Number of data } \\
\text { points provided } \\
\text { - Self-reported } \\
\text { persuasiveness }\end{array}$ & $\begin{array}{l}\text { - Registration } \\
\text { Completion } \\
\text { - Number of data } \\
\text { points provided } \\
\text { - Self-reported } \\
\text { persuasiveness }\end{array}$ \\
\hline
\end{tabular}

Note: This study included between-subject independent variables (gender and risk-attitude) constituting six different groups, along with within-subject independent variables (persuasive mechanics). Dependent variables measured (registration completion, number of data points provided, and self-reported persuasiveness score) are also shown. Additionally, participants were asked to explain their answers to gather qualitative data for further insights. Also, they were asked, after seeing all designs, which they felt was the most persuasive, if any and why. 


\section{Participants}

Utilizing $\mathrm{G}^{*}$ Power, power analysis was conducted and a sample size of 126 was determined as the necessary number of participants (see Figure 5). Due to time constraints, only 40 participants actually participated in the study.

Local community members were asked to participate in this study.

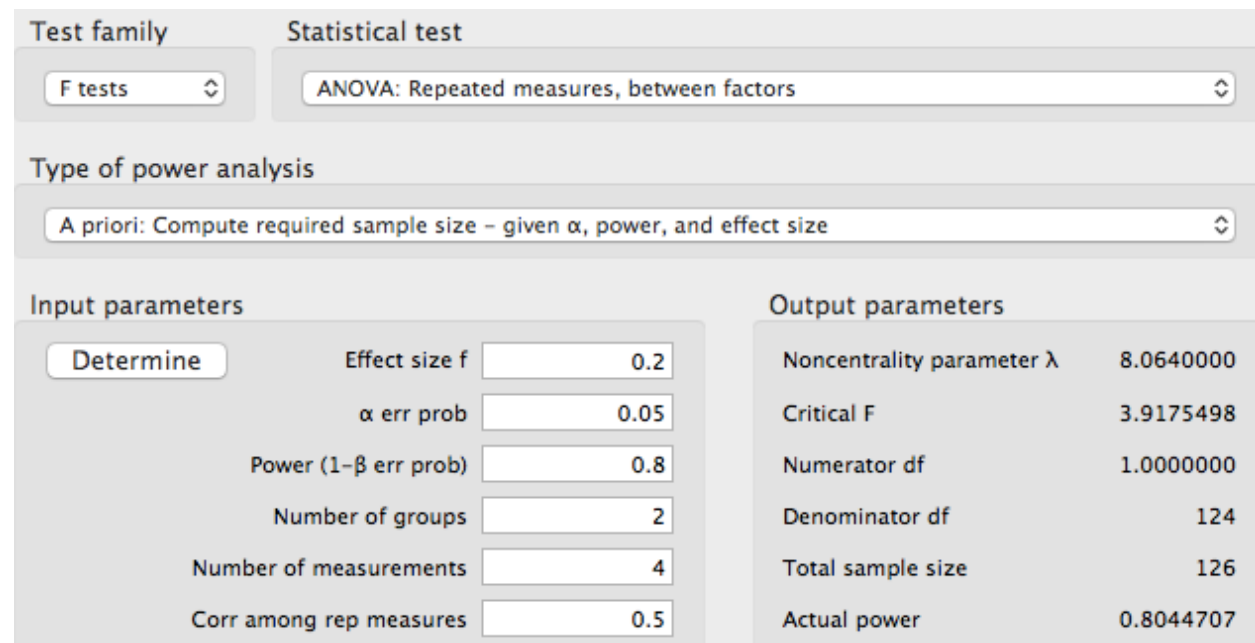

Figure 5. Power analysis using $\mathrm{G}^{*}$ Power.

\section{Apparatus}

A recruiting survey was used to recruit participants (Appendix A).

Instructions to participants including a scenario was read to participants (Appendix B).

An informed consent form (Appendix C.)

The Risk Attitudes Profiler was given to determine risk-taking attitudes (Appendix D).

A list of "friends" was provided to participants (Appendix E). 
Four mock registrations (Appendix F-I) for all conditions of persuasive mechanics were created in the Axure prototyping tool and displayed on a 15" MacBook Air using the Firefox web browser.

The persuasiveness question and scale asked of participants (Appendix J).

A counterbalancing tracking sheet (Appendix K).

A note-taking/data sheet was used to collect data (Appendix L).

\section{Procedures}

In order to assure that an equal number of male and female participants, potential participants were recruited by taking a survey (utilizing Google) that required their name, gender, email, phone number, potentially available times (for scheduling sessions), (Appendix A).

Participants were read instructions from a script (Appendix B) and asked to sign a consent form (Appendix C) stating that they were willingly participating in this experiment. They were then asked to take the Risk Attitudes Profiler (Appendix D) and their result was recorded.

Participants were then briefed on the fact that they would be filling out a series of four different, short online registrations for a new social networking site and answering a short question after each registration. They were instructed that the session would last about 45 minutes and that they could choose to quit participating at any time.

Participants were then read a scenario (Appendix B). They also received a list of fake friends that had already joined the site (Appendix E). They were further instructed that they 
could choose not to provide certain information and that they should stop entering information and quit the registration if at any time if they felt like they would take this action normally.

Participants were then instructed to fill out the first online registration (Appendix F-I).

Upon completion of the first registration, or if they quit, participants were shown and asked to answer a question about their perceived persuasiveness of the registration and why they felt the design was persuasive or not (Appendix J).

This was repeated three more times with all variations of the registration (no persuasive mechanics, praise persuasive mechanic, social-pressure persuasive mechanic, and both persuasive mechanics) (Appendix F-I). The order in which participants were shown these variations was counterbalanced. The amount of data provided in terms of data-points was tallied as the participants provided them during each registration. Whether or not participants complete the registration for any given variation was also recorded.

After participants viewed all designs, they were then asked which design they felt was more persuasive, if any, and why.

In regards to participant privacy and data protection, the recruitment survey was a password-protected Google survey that was only used for recruiting. Once all research sessions were successfully conducted, this data was permanently deleted. Each participant was identified as a number. Along with this number, their gender and risk-attitude level was recorded. Additionally, the number of data points they provided during each of the four registrations as well as whether or not they completed each registration was recorded along with the number. Also, their self-reported persuasiveness score was recorded for each design. None of the personal 
information supplied while filling out the mock registrations was stored in any way. As soon as each page of the registration was submitted, the data is gone (Appendix L). 


\section{Chapter 4}

\section{RESULTS}

40 participants took part in the study. Every single participant completed every registration, so an analysis on registration completion rates was not necessary as none of the independent variables had an effect on this.

Because this study incorporated multiple independent variables (gender, risk-attitude, and persuasive mechanics) and multiple dependent variables (number of data points provided and self-reported persuasiveness scores), and because persuasive mechanics were studied via a within-subjects, repeated-measure design, and gender and risk-attitudes were studied via a between-subjects design, an omnibus repeated-measures MANOVA was conducted with SPSS. Additionally, because most variables had more than two groups, Wilks' Lambda adjusted for MANOVA was used for analysis.

After experiencing all designs, participants were asked to identify the design they thought was the most persuasive, if any. Due to the categorical nature of this data, a chi-squared method was used to analyze it.

\section{Gender Main Effects}

Differences between number of data points, and differences between perceived perception ratings provided by different genders were investigated and showed that men provided more data and rated the designs higher than women did (Table 2). 
Table 2

Descriptive Statistics of Gender

\begin{tabular}{lcccccc}
\hline & & \multicolumn{2}{c}{ Data points } & & \multicolumn{2}{c}{ Persuasive Ratings } \\
\cline { 3 - 4 } Gender & $n$ & $M$ & $S E$ & & $M$ & $S E$ \\
\hline Male & 22 & 18.53 & 2.40 & & 4.22 & 0.37 \\
Female & 18 & 15.50 & 1.91 & & 4.19 & 0.30
\end{tabular}

These differences, however, were not statistically significant, indicating no main effect for gender, Wilks' $\Lambda=0.97, F(2,33)=0.48, p=0.62$.

\section{Risk Attitudes Main Effects}

Differences between the number of data points provided, and differences between perceived perception ratings provided by participants with different risk attitudes were investigated and showed that risk-avoiders provided the most data points overall for all designs, while risk-seekers thought the designs were more persuasive overall (Table 3).

Table 3

Descriptive Statistics of Risk Attitudes

\begin{tabular}{|c|c|c|c|c|c|}
\hline \multirow[b]{2}{*}{ Risk Attitudes } & \multirow[b]{2}{*}{$n$} & \multicolumn{2}{|c|}{ Data points } & \multicolumn{2}{|c|}{ Persuasive Ratings } \\
\hline & & $M$ & $S E$ & $M$ & $S E$ \\
\hline Risk-Avoiders & 5 & 19.47 & 3.51 & 4.13 & 0.55 \\
\hline Moderate Risk Takers & 29 & 14.89 & 1.19 & 3.99 & 0.18 \\
\hline Risk-Seekers & 6 & 16.72 & 2.72 & 4.50 & 0.42 \\
\hline
\end{tabular}

These differences were not statistically significant however, indicating no main effect for risk attitude, Wilks' $\Lambda=0.92, F(4,66)=0.92, p=0.61$.

\section{Persuasive Mechanic Main Effect}

Probably of most interest, were the effects of persuasive mechanics on the number of data points provided and perceived persuasion. Difference between data points provided by the 
subjects, and differences between rated persuasion scores were analyzed across the different persuasive mechanics. Overall, the praise mechanic elicited the most data from people, while participants felt that both mechanics combined was the most persuasive (Table 4).

Table 4

Descriptive Statistics of Persuasive Mechanic Designs

\begin{tabular}{lccccc}
\hline & \multicolumn{2}{c}{$\begin{array}{c}\text { Data Points } \\
\text { Provided }\end{array}$} & & \multicolumn{2}{c}{$\begin{array}{c}\text { Persuasive } \\
\text { Ratings }\end{array}$} \\
\cline { 2 - 3 } \cline { 5 - 6 } \multicolumn{1}{c}{ IV } & $M$ & $S E$ & & $M$ & $S E$ \\
\hline No-Mechanics & 15.53 & 6.04 & & 4.17 & 0.90 \\
Praise & 15.73 & 6.39 & & 4.07 & 0.94 \\
Social Pressure & 15.33 & 6.45 & & 4.00 & 1.40 \\
Both & 14.55 & 6.83 & & 4.20 & 1.57
\end{tabular}

There was no statistical significance between any persuasive mechanics for the number of data points provided, nor the self-reported perceived perception scores, indicating no main effect, Wilks' $\Lambda=0.72, F(6,29)=1.86, p=0.12$.

\section{Gender \& Risk Attitudes Interactive Effects}

The interactive effect of gender and risk attitudes on the number of data points provided and perceived persuasion was also of interest. Therefore differences in the number of data points provided and differences in the self-reported persuasiveness scores were looked at. This analysis showed that risk-avoiding men provided the most data (though there was only one in this study), and that risk-seeking men and women tied for thinking designs were overall more persuasive than other groups of people (Table 5). 
Table 5

Descriptive Statistics of Gender and Risk Attitudes Groupings (Gender * Risk Attitudes)

\begin{tabular}{|c|c|c|c|c|c|}
\hline \multirow[b]{2}{*}{ IV Groupings } & \multirow[b]{2}{*}{$n$} & \multicolumn{2}{|c|}{ Data points } & \multicolumn{2}{|c|}{ Persuasive Ratings } \\
\hline & & $M$ & $S E$ & $M$ & $S E$ \\
\hline \multicolumn{6}{|l|}{ Males } \\
\hline Risk-Avoiders & 1 & 25.00 & 6.29 & 4.00 & 0.97 \\
\hline Moderate Risk Takers & 17 & 14.97 & 1.53 & 4.16 & 0.24 \\
\hline Risk-Seekers & 4 & 15.69 & 3.15 & 4.50 & 0.49 \\
\hline \multicolumn{6}{|l|}{ Females } \\
\hline Risk- Avoiders & 4 & 13.94 & 3.15 & 4.25 & 0.49 \\
\hline Moderate Risk Takers & 12 & 14.81 & 1.82 & 3.81 & 0.28 \\
\hline Risk-Seekers & 4 & 17.75 & 4.45 & 4.50 & 0.69 \\
\hline
\end{tabular}

There was no statistical significance between any gender/risk attitudes groups for the number of data points provided, nor the self-reported perceived persuasiveness scores, indicating that there were no interactive effects, Wilks' $\Lambda=0.92, F(4,66)=0.73, p=0.57$.

\section{Persuasive Mechanic \& Gender Interactive Effect}

Again, of more notable interest, was the effect that different persuasive mechanics may have on different genders. Data showed that a praise mechanic elicited more data output from men, while women provided more data with a social-pressure mechanic. Men felt that both mechanics applied together was most persuasive, while women felt the social-pressure mechanic alone was most persuasive (Table 6). 
Table 6

Descriptive Statistics of Persuasive Mechanic Designs by Gender

\begin{tabular}{lccccc}
\hline & \multicolumn{2}{c}{$\begin{array}{c}\text { Data Points } \\
\text { Provided }\end{array}$} & & \multicolumn{2}{c}{$\begin{array}{c}\text { Persuasive } \\
\text { Ratings }\end{array}$} \\
\cline { 2 - 3 } \cline { 6 - 6 } IV Groupings & $M$ & $S E$ & & $M$ & $S E$ \\
\hline Males $(n=22)$ & & & & & \\
No-Mechanics & 17.50 & 2.43 & & 4.14 & 0.36 \\
Praise & 19.11 & 2.46 & & 4.19 & 0.37 \\
Social Pressure & 18.75 & 2.47 & & 4.15 & 0.54 \\
Both & 18.85 & 2.68 & & 4.41 & 0.62 \\
Females $(n=18)$ & & & & & \\
No-Mechanics & 14.97 & 1.94 & & 4.06 & 0.29 \\
Praise & 16.33 & 1.96 & & 4.28 & 0.29 \\
Social Pressure & 16.56 & 1.97 & & 4.44 & 0.43 \\
Both & 14.14 & 2.14 & & 3.97 & 0.50
\end{tabular}

There was no statistical significance between any persuasive-mechanics/gender groupings for the number of data points provided, nor the self-reported perceived perception scores, indicating no interactive effect, Wilks' $\Lambda=0.84, F(6,29)=0.94, p=0.48$.

\section{Persuasive Mechanic \& Risk Attitude Interactive Effect}

It was highly suspected that people with various attitudes towards risk would respond differently to different persuasive mechanics. Data shows that both mechanics applied was most persuasive for risk-avoiders in terms of the amount of data they supplied, while they found the social-pressure mechanic to be most persuasive. Moderate risk takers provided the most information with no-mechanics applied at all and felt this was the most persuasive as well, while risk-seekers supplied the most data points with a social-pressure mechanic and thought it was the most persuasive approach. 
Table 7

Descriptive Statistics of Persuasive Mechanic Designs by Risk Attitude

\begin{tabular}{lccccc}
\hline & \multicolumn{2}{c}{ Data Points } & & \multicolumn{2}{c}{ Persuasive Ratings } \\
\cline { 2 - 3 } \cline { 5 - 6 } IV Groupings & $M$ & $S E$ & & $M$ & $S E$ \\
\hline Risk-Avoiders $(n=5)$ & & & & \\
$\quad$ No-Mechanics & 17.88 & 3.56 & & 4.13 & 0.52 \\
Praise & 19.75 & 3.61 & & 4.00 & 0.54 \\
$\quad$ Social Pressure & 19.88 & 3.62 & & 4.25 & 0.80 \\
$\quad$ Both & 20.38 & 3.93 & & 4.13 & 0.91 \\
Moderate Risk Takers $(n=29)$ & & & & & \\
$\quad$ No-Mechanics & 15.33 & 1.20 & & 4.16 & 0.18 \\
$\quad$ Praise & 15.29 & 1.22 & & 3.95 & 0.18 \\
$\quad$ Social Pressure & 14.83 & 1.22 & & 3.77 & 0.27 \\
$\quad$ Both & 14.11 & 1.33 & & 4.07 & 0.31 \\
Risk-Seekers $(n=6)$ & & & & & \\
$\quad$ No-Mechanics & 15.50 & 2.76 & & 4.00 & 0.41 \\
$\quad$ Praise & 18.13 & 2.79 & & 4.75 & 0.42 \\
Social Pressure & 18.25 & 2.80 & & 4.88 & 0.62 \\
$\quad$ Both & 15.00 & 3.05 & & 4.38 & 0.71
\end{tabular}

There was however no statistical significance between any persuasive-mechanic/riskattitude groupings for the number of data points provided, nor the self-reported perceived perception scores, indicating no interactive effect, Wilks' $\Lambda=0.64, F(12,58)=1.23, p=0.29$.

\section{Persuasive Mechanic, Risk Attitude, \& Gender Interactive Effect}

Breaking groups down further to see if there were different effects elicited by the various mechanics on different genders, risk-taking attitude combinations. The one male, risk-avoider provided the most information with both mechanics applied, and felt all designs were equally persuasive. The male moderate risk takers provided the most information with the no-mechanics treatment, but felt that both mechanics applied was the most persuasive. The male risk-seekers provided the most information with the social-pressure mechanic and felt it, along with both applied provided the most persuasive designs. Female risk avoiders provided the most information with no-mechanics, but felt that the social-pressure mechanic was the most 
persuasive. Women moderate risk takers provided the most information with the social-pressure mechanic, but felt that no-mechanics was the most persuasive. Lastly, women risk-seekers provided the most information with the praise and social-pressure designs, and felt they were the most persuasive (Table 8).

There was no statistical significance between any persuasive-mechanic/riskattitude/gender groupings for the number of data points provided, nor the self-reported perceived perception scores, indicating no interactive effect, Wilks' $\Lambda=0.53, F(12,58)=1.80, p=0.07$. This appears to be approaching significance however. 
Table 8

Descriptive Statistics of Persuasive Mechanic Designs by Risk Attitude and Gender

\begin{tabular}{|c|c|c|c|c|}
\hline \multirow{2}{*}{ IV Groupings } & \multicolumn{2}{|c|}{ Data Points } & \multicolumn{2}{|c|}{ Persuasive Ratings } \\
\hline & $M$ & $S E$ & $M$ & $S E$ \\
\hline \multicolumn{5}{|l|}{ Males } \\
\hline \multicolumn{5}{|l|}{ Risk-Avoiders $(n=1)$} \\
\hline No-Mechanics & 21.00 & 6.37 & 4.00 & 0.94 \\
\hline Praise & 26.00 & 6.45 & 4.00 & 0.96 \\
\hline Social Pressure & 26.00 & 6.47 & 4.00 & 1.42 \\
\hline Both & 27.00 & 7.03 & 4.00 & 1.63 \\
\hline \multicolumn{5}{|c|}{ Moderate Risk Takers $(n=17)$} \\
\hline No-Mechanics & 16.00 & 1.55 & 4.41 & 0.23 \\
\hline Praise & 15.59 & 1.56 & 4.06 & 0.23 \\
\hline Social Pressure & 14.24 & 1.57 & 3.71 & 0.35 \\
\hline Both & 14.06 & 1.71 & 4.47 & 0.40 \\
\hline \multicolumn{5}{|l|}{ Risk-Seekers $(n=4)$} \\
\hline No-Mechanics & 15.50 & 3.18 & 4.00 & 0.47 \\
\hline Praise & 15.75 & 3.23 & 4.50 & 0.48 \\
\hline Social Pressure & 16.00 & 3.24 & 4.75 & 0.71 \\
\hline Both & 15.50 & 3.52 & 4.75 & 0.82 \\
\hline \multicolumn{5}{|l|}{ Females } \\
\hline \multicolumn{5}{|l|}{ Risk-Avoiders $(n=4)$} \\
\hline No-Mechanics & 14.75 & 3.18 & 4.25 & 0.47 \\
\hline Praise & 13.50 & 3.23 & 4.00 & 0.48 \\
\hline Social Pressure & 13.75 & 3.26 & 4.50 & 0.71 \\
\hline Both & 13.75 & 3.52 & 4.25 & 0.82 \\
\hline \multicolumn{5}{|c|}{ Moderate Risk Takers $(n=12)$} \\
\hline No-Mechanics & 14.67 & 1.84 & 3.92 & 0.27 \\
\hline Praise & 15.00 & 1.86 & 3.83 & 0.28 \\
\hline Social Pressure & 15.42 & 1.87 & 3.83 & 0.41 \\
\hline Both & 14.17 & 2.03 & 3.67 & 0.47 \\
\hline \multicolumn{5}{|l|}{ Risk-Seekers $(n=2)$} \\
\hline No-Mechanics & 15.50 & 4.50 & 4.00 & 0.66 \\
\hline Praise & 20.50 & 4.56 & 5.00 & 0.68 \\
\hline Social Pressure & 20.50 & 4.58 & 5.00 & 1.01 \\
\hline Both & 14.50 & 4.97 & 4.00 & 1.15 \\
\hline
\end{tabular}

\section{Chi-Square of Most Persuasive Design}

Participants were asked at the end of the study, having seen all the designs, which one they felt was the most persuasive, if any, and why. Overall, the majority felt that the no- 
mechanic design was the most persuasive, followed by a large number who selected the social mechanic as the most persuasive (Table 9).

Table 9

Frequencies of participant-selected designs as the most persuasive

\begin{tabular}{lccccc}
\hline & None & No-Mechanic & Praise & Social & Both \\
\hline Frequencies & 5 & 19 & 2 & 14 & 0 \\
\hline
\end{tabular}

To see if gender had any affect on this, these numbers were broken up by gender for further analysis. Interestingly, men felt the no-mechanic design was most persuasive overall, while women mostly felt the social mechanic was most persuasive (Table 10).

Table 10

Frequencies of participant-selected designs as the most persuasive by gender

\begin{tabular}{lccccc}
\hline & None & No-Mechanic & Praise & Social & Both \\
\hline Males & 2 & 13 & 1 & 6 & 0 \\
Females & 3 & 6 & 1 & 8 & 0 \\
\hline
\end{tabular}

Risk attitudes were also looked at to see if differences existed here. Risk avoiders were evenly split between none (not thinking any design was most persuasive) and the social-pressure mechanic. Moderate risk takers felt that the no-mechanic design was most persuasive, while riskseekers felt the social mechanic was most persuasive (Table 11).

Table 11

Frequencies of participant-selected designs as the most persuasive by risk attitude

\begin{tabular}{lccccc}
\hline & None & No-Mechanic & Praise & Social & Both \\
\hline Risk-Avoiders & 2 & 1 & 0 & 2 & 0 \\
Moderate & 2 & 17 & 2 & 8 & 0 \\
Risk-Seekers & 1 & 1 & 0 & 4 & 0 \\
\hline
\end{tabular}

Lastly, the interaction between gender and risk attitudes was of interest in this investigation. Male risk-avoiders (only one participant) and the male moderate risk takers felt the no-mechanic design was most persuasive. Male risk-seekers and female risk-avoiders felt the 
social mechanic was most persuasive. Lastly, female moderate risk takers and female riskseekers were split between the no-mechanic design, and the social-pressure mechanic (Table 12).

Table 12

Frequencies of participant-selected designs as the most persuasive by gender and risk attitude

\begin{tabular}{lccccc}
\hline & None & No-Mechanic & Praise & Social & Both \\
\hline Male & & & & & \\
$\quad$ Risk-Avoiders & 0 & 1 & 0 & 0 & 0 \\
Moderate & 1 & 12 & 1 & 3 & 0 \\
$\quad$ Risk-Seekers & 1 & 0 & 0 & 3 & 0 \\
Female & & & & & \\
$\quad$ Risk-Avoiders & 2 & 5 & 0 & 2 & 0 \\
Moderate & 1 & 1 & 1 & 5 & 0 \\
Risk-Seekers & 0 & 5 & 0 & 1 & 0 \\
\hline
\end{tabular}

Assuming an equal number of expected selections for each mechanic, chi-square was conducted to see if the differences between mechanics were significant. Results indicate that they were significant indicating that the frequency of the selection of mechanics as the most persuasive by participants were not equal, $x^{2}(4)=18.60, p<0.01$. When looking at the data, it is clear that the no-mechanic design was selected as the most persuasive by participants, followed by the social mechanic as a close second. Deeper analysis into whether differences in selections based on gender, risk attitudes, and the combination of the two was not able to be calculated due to unequal sizes in groups and small numbers within the groups.

Participants were asked to explain their selection. Most notably, 13 of the 19 participants who selected the no-mechanic design as the most persuasive indicated that they felt the socialpressure mechanic was off-putting, namely that it felt pushy. Four of the 19 indicated that they simply found the simplicity of the design more appealing and therefore more persuasive. The remaining two who selected the no-mechanic design, said that its background color appealed to them most, which they felt was persuasive. In order to help participants distinguish between 
designs, different background colors were used. This obviously ended up becoming a confounding variable.

All 13 of the 14 of those who selected the social-mechanic design as the most persuasive indicated that knowing that the vast majority of people (with percentage persuasion) was comforting and/or knowing what interests their friends were interested in was useful knowledge. One indicated background color as the persuasive factor here.

The five who selected "none", didn't feel any design was more persuasive than the others. While one participant who selected the praise mechanic indicated that the humor was pleasing and therefor persuasive. The other participant who selected the praise mechanic indicated the background color as the deciding factor.

A large portion of participants also noted that they never noticed a difference between the no-mechanic design, and the praise design, indicating that they did not see the praise messages at the top of the screen. Unfortunately exact numbers for this were not collected.

\section{Evaluation of Hypothesis}

The results for the MANOVA for the quantitative dependent variables (data-points entered and persuasiveness score) showed no statistically significant differences in data provided, nor self-reported persuasion scores between gender, risk attitude, persuasive mechanic, nor any combination thereof.

However, qualitative data (most persuasive design selected by participants) showed that participants ultimately felt that some designs (no-mechanics and the social-pressure mechanic) were more persuasive than others. 
Therefore, all hypotheses are rejected. Namely, a combination of mechanics (both) was not more successful than single-mechanic or no-mechanic designs in increasing registration completions rates, eliciting more data from participants, nor increasing their perception of persuasiveness. Additionally, different groups of people (segmented by gender and risk-taking attitudes) and combinations thereof were not influenced differently by different persuasive mechanics as applied in this particular design in terms of the amount of data they provided nor their perception of persuasion. 


\section{Chapter 5}

\section{DISCUSSION}

The goal of this study was to determine how effective two different persuasive mechanics (praise \& social pressure) were in persuading people to provide information about themselves in an applied setting (social network registration), and whether a combination of techniques would be most persuasive. Previous research had shown that computers could be used effectively to persuade people to different beliefs and actions, but none had shown whether particular persuasive mechanics were more effective than others, nor did any attempt to apply persuasive mechanics to applied settings. Furthermore, none of these looked at other factors that might influence persuasion, such as risk-taking attitudes or gender. Even though work by Weiksner, Fogg, \& Liu (2008) categorized Facebook persuasive mechanics, they did not attempt to determine whether or not such mechanics were effective at all, or whether some were more effective than others.

It was hypothesized that the combination of mechanics would be the most persuasive as measured by the amount of data supplied by users during each registration and their ratings on a persuasiveness scale. Furthermore it was hypothesized that different mechanics may have different effects on different groups of people. None of these hypotheses were statistically supported by the data however. Participants were asked at the end of each session which design they felt was most persuasive, if any, and this did show statistically significant results however.

Though men provided more data and felt all designs were overall more persuasive than women did, this result was not statistically significant and likely due to sampling error. Nevertheless, looking into this further, perhaps with a larger sample size, might prove to be a 
worthy endeavor. It begs the question of whether men are more willing to take risk in general than women are, and whether or not they're more susceptible to persuasion with the use a praise or social pressure mechanics. If the difference were really due to gender, it would be interesting to attempt to figure out why this might be.

In looking at risk attitude, risk-avoiders provided the most data points overall for all designs. This would seem to be counter-intuitive, however, this difference was not statistically significant and likely due to sampling error. Nevertheless, it does draw into question whether general attitudes towards risk taking is an adequate factor to consider. It was noted through qualitative data that several participants who were risk-seekers, for example, indicated that though they like taking risks in general, the risk involved in providing personal data on the Internet was not one of the risks they enjoyed or actively engaged in. Perhaps a more specific measure such as online risk behavior and attitudes would have been a more suitable metric to consider. Additionally, it is unknown whether the Risk Attitudes Profiler is a validated measure. Utilizing validated measures that look closer at online risk attitudes would be advised for future research.

The effect of persuasive mechanic had some interesting results. Overall, participants provided the most data with the praise mechanic, while they rated the combination of both mechanics as the most persuasive. These were not shown to be statistically significant, though they seemed to be approaching significance with a p-value of 0.12 . After completing all registrations, they were asked which design they felt was most persuasive, and most selected the no-mechanic design as the most persuasive. This was statistically significant. Additionally, at the end of the study, several participants indicated that they did not notice a difference between the no-mechanic design, and the praise-mechanic design, indicating a possible banner-blindness 
effect, since the praise mechanic was shown at the very top of the screen. Further research could be conducted into mechanic text placements, text treatments, phrases, and wording, etc. to see how these might have an effect on the persuasiveness of each type of mechanic.

Nevertheless, these are truly interesting results. They draw into question whether or not humans are actually aware that they are being persuaded. Several participants didn't seem to consciously notice the praise-mechanic. So, is it possible that they did notice it, but only subconsciously, and thus this did persuade them into providing the most data when compared to other mechanics? Or perhaps it was the most persuasive for those who did notice it, but they weren't aware of this persuasive effect and therefore didn't rate it as persuasive as other mechanics or select it as the most persuasive design. Qualitative data showed a pretty even split among participants regarding the social pressure mechanic. Some indicated that this compelled them to finish steps, supply information, or even to follow interests that friends were following, while others felt the mechanic was "pushy" and overbearing. Perhaps this had something to do with the manner in which the mechanic was implemented. Additionally, it could make one wonder whether this split was dependent upon some other variable, like risk attitude, gender, or both combined - indicating possible interactive effects between independent variables.

In looking at effects between the interactions of gender and persuasive mechanic, men supplied more information with the praise mechanic, while women did so with the socialpressure mechanic. Men rated the both-mechanic design as the most persuasive, but women rated the social-pressure mechanic as the most persuasive. These differences however were far from statistical significance with a p-value of 0.48 . Nevertheless, if these differences were due to the interaction, it is interesting to note that this aligns with commonly held stereotypes that men love to have their egos stroked, while women are much more social in nature. Investigating this 
further with a larger sample size is advised, as the implications are great. If gender is a factor in terms of which mechanic is most persuasive, and social networks were to capture gender in the first step of their registrations, like they currently do, they could tailor the mechanics utilized based on gender quite easily.

Furthermore, the effects of the interaction between risk attitude and design showed some interesting results as well. Risk-avoiders provided the most data with both mechanics applied, but rated the social-pressure mechanic as the most persuasive. Moderate risk takers provided the most information with no-mechanics applied at all and felt this was the most persuasive as well, while risk-seekers supplied the most data points with a social-pressure mechanic and thought it was the most persuasive approach. Again, the difference between these was not statistically significant, though it appeared to be approaching significance, more so than the interaction between gender and mechanic, with a p-value of 0.29. Again, a more specific measure of risk attitudes regarding online activity/privacy, as well as a larger sample size might show clearer results here.

Lastly, the difference between groups regarding the interaction between all three independent variables (mechanic, gender, and risk-attitude) approached significance with a pvalue of 0.07 , indicating that though gender or risk attitude interactions with mechanic were not statistically significant, the interaction of all three variables almost is. Several of these groups were quite small however, often containing one or two people. It is therefore recommended to investigate this further with a larger sample size.

Additionally, in hindsight, it would have been useful perhaps to look at age as a possible factor. All of the major social network sites require name, email, password, gender, and age as 
part of the first step in their registrations. If knowing about any age-mechanic interactions along with gender would enable these sites to tailor the persuasive mechanics utilized in subsequent steps to those most effective for each gender-age group.

Overall, when participants were asked after looking at all designs, which they felt was most persuasive, the vast majority selected the no-mechanic design, and this was statistically significant based on chi-square analysis. Participants were also asked why they selected the designs they did, and most indicated that they either liked the simplicity of no-mechanics, or that they felt the other designs were "pushy". This measure however may be problematic in that it is both retrospective and subjective. As the end result for social networks is to actually get the most data, more objective measures, like the amount of data participants actually supplied are much more telling. Additionally, participants were asked this question after seeing all designs and realizing that there was an attempt to persuade them to supply more information than they might have normally. Being aware of this seemed to make participants uneasy. They simply didn't like the fact that they were intentionally manipulated, however, after filling out each registration, several of them did rate other designs as more persuasive than the no-mechanic design. For this reason, not using a retrospective, subjective measure, along with a much larger sample size utilizing a strict between-subject design and focusing on objective data solely might prove to provide more concrete data into how the specific mechanics actually affect behavior, thereby providing actionable insights. Looking at a subjective measure regarding the like or dislike of certain mechanics for various groups may prove helpful too, as a strong negative emotional reaction to any mechanic would provide a poor user experience that would not be desired and therefore should be avoided. 
In regard to the praise mechanic, of those who did seem to notice it, qualitative data showed that some felt the praise was not genuine, which had a negative effect, while others felt the praise was "silly" or "funny" which had a positive effect. Again, using a larger sample size and potentially looking at this effect among different groups, particularly based on age and gender, may prove helpful. This also brings to light that the phrasing of praise, and variations thereof might be perceived differently overall and by different groups of people. The placing of the text may also have an effect based on this data. Further research into the specific implementations of these mechanics and variations thereof is also recommended.

Furthermore, it was noted that several participants seemed to suffer from a fatigue effect. Several expressed some signs of annoyance, frustration, and boredom with filling out what many viewed as essentially the same registration four times in a row. Again, utilizing a larger sample size with a strict between-subject design would eliminate this.

Also, a small handful of participants indicated being influenced by the background color. Different background colors were chosen in an attempt to help participant distinguish between designs and give them a point of reference when selecting the design they felt was most persuasive at the end of the session. This ended up creating a confounding variable that should be avoided in future studies.

Additionally, a couple of other notable occurrences took place. A couple of participants skipped almost every step. They indicated that they weren't active social network users and weren't interested in social networking, bringing to light that initial motivation or intrinsic motivation to signing up is an important key step, and should be considered for removal from future studies when screening participants, or running them as a separate group to see if 
persuasive mechanics have any effect on them at all in spite of their lack of initial motivation. Also, almost no one chose to import contacts. This method of finding large groups of friends is available on all of the major social network registrations, yet very few opted to do so. This indicates a possible direction for future research into what, if any mechanics might be most persuasive for a step that most people skip and avoid.

Lastly, participants were aware that this was a fake registration, which may have altered their behavior. If possible, research using real social network registrations would be advisable. 


\section{References}

Aristotle (350 B.C.) Rhetoric (Vol. 1) (W. R. Roberts, Trans.). Retrieved from http://classics.mit.edu/Aristotle/rhetoric.1.i.html

Baumeister R. F., \& Leary, M. R. (1995) The need to belong; desire for interpersonal attachments as a fundamental human motivation. Psychological Bulletin 117(3), 497-529.

Fogg, B. J. (2003). Persuasive technology: using computers to change what we think and do. Burlington: Morgan Kaufmann Publishers.

Fogg, B. J. (1998). Persuasive computers: perspectives and research directions. Proceedings of the CHI 98 Conference on Human Factors in Computer Systems, Los Angeles.

Fogg, B. J., \& Nass, C. (1997a, March). How users reciprocate to computers: an experiment that demonstrates behavior change. In Extended Abstracts of CHI'97 (pp. 331-332).

Fogg, B. J., \& Nass, C. (1997b). Silicon sycophants: the effects of computers that flatter. International Journal of Human-Computer Studies 46, 551-561.

Gouldner, A. W. (1960). The norm of reciprocity: a preliminary statement. American Sociological Review, 25(2), 161-178.

Leary, M. R., \& Kowalski, R. M. (1990). Impression management: a literature review and twocomponent model. Psychological Bulletin, 107(1), 34-47.

Marshall, C. \& Maguire, T. (1971) The computer as social pressure to produce conformity in a simple perceptual task. AV Communication Review 19(1), 19-28.

Nass, C., Fogg, B. J., \& Moon, Y. (1996). Can computer be teammates? International Journal of Human-Computer Studies 45, 669-678.

Nass C., Moon, Y., Fogg, B. J., Reeves, B., \& Dryer, C. (1995). Can computer personalities be human personalities? International Journal of Human-Computer Studies, 43, 223-239

Oinas-Kukkonen, H. \& Harjumma, M. (2009). Persuasive systems design: key issues, process model, and system features. Communications of the Association for Information Systems, $24,485-500$.

Weiksner, G. M., Fogg, B. J., \& Liu, X. (2008) Six patterns for persuasion in online social networks. In Oinas-Kukkonen, H., Hasle, P., Harjumaa, M., Segerståhl, K., \& Øhrstrøm, P. (Eds.), Persuasive Technology, Proceedings of the Third International Conference, Finland, (pp. 151-163). 


\section{Appendix A. Recruiting Survey}

Thank you for your interest in participating in this study. In order to be considered for participation, please follow the instructions below to complete this survey. All personalidentifiable information supplied here is confidentially password protected and will be deleted upon completion of the study.

What is your name?

Please specify your gender: $\mathrm{M} / \mathrm{F}$

What is your email and number (for scheduling purposes)?

Which of the following times are you potentially available to participate in a 1-hour session?

Mon. evenings

Tue. evenings

Wed. evenings

Thurs. evenings

Fri. evenings

Sat. mornings

Sat. afternoons

Sat. evenings

Sun. mornings

Sun. afternoons

Sun. evenings

Thank you, if selected to participate you will be emailed or called for scheduling. 


\section{Appendix B. Instructions to Participants}

"Before we begin today, I need you to read and sign this consent form." [give participant a copy of the consent form]

"Now, I would like to have you take a short survey regarding your attitudes towards taking risks." [administer the Risk Attitudes Profiler]

"Today we will be looking at four different registrations for a new social networking site called Connection+. You will fill out each registration and answer a short question before proceeding to the next survey.

I want you to pretend that you have heard of a new social networking site called Connection+ and a few of your friends have told you that you should join the site. Specifically your friends Julie Spoon, Jeremy Knife, James Fork, and Katrina Glass have already joined. [Give friend list] Here is a list of their names to refresh your memory later. [Pull up registration] You've navigated your computer to the home screen and have clicked on the "register" button.

If you do not feel compelled to provide certain information, you may refrain from doing so. If at any time you would quit the registration and not continue, please stop where you would and let me know.

Go ahead and fill out the first registration. [record the number of data-points provided and whether or not the participant completes the registration or quits]

[Once the participant has complete the registration or quit]

Great, now I'm going to ask you a question, simply verbally answer the question based on the provided scale. [Give participant question sheet] To what extent did you feel compelled to provide information and complete the registration? [record response]. Why? [record response]

Thank you. We will now proceed to the next registration. [Pull up next registration]

Pretend once again that you're visiting the site for the first time and that you have not previously registered. You've navigated your computer to the home screen and have clicked on the "register" button.

Go ahead and fill out this registration.

[repeat for all registrations]

[after participant has filled out/looked at all registrations]:

Of all of the designs, which one do you feel was the most persuasive, if any? Why? [record answer]

Thank you for your participation in the study today. Here is your gift card [Dismiss participant] 


\section{Appendix C. Consent Form}

\section{REQUEST FOR YOUR PARTICPATION IN RESEARCH}

\section{AN INVESTIGATION OF THE EFFECTIVENESS OF PERSUASIVE MECHANICS IN SOCIAL NETWORK REGISTRATIONS}

Nathan Cook, San Jose State Graduate Student

\section{PURPOSE}

The purpose of this study is to investigate the effectiveness of techniques used by corporations in persuading people to supply information about themselves during registration. Also of interest is whether the degree to which the effectiveness of these techniques vary based on gender and risk-engagement attitudes and behavior. More and more, in order to maintain free services, businesses, such as social networking sites, require more information of you so that they can show you advertisements that are related to your interests. Their effectiveness in doing so directly affects the quality of free services they are able to provide you. The more information they are able to solicit from you, the more they are able to provide you with quality, free services.

\section{PROCEDURES}

The session will take place on San Jose State University campus and will last about one hour. You will be asked to take a short survey that assess how willing you are to engage in risky behavior.

You will then be read a scenario and then be presented with a social network registration on a computer and asked to fill it in and provide the information that you normally would. If you wish to not supply certain information, or quit the registration altogether, you may wish to do so.

You will then be asked a few questions about your experience.

You will then be asked to do this 3 additional times with different versions of the registration.

The amount of information you supply will be recorded by the researcher, but no video, audio, or screen shots will be taken.

\section{POTENTIAL RISKS}

As this study only involves normal computer use, there are no foreseeable risks involved with this study.

\section{POTENTIAL BENEFITS}

By participating in this study, you will be contributing to the general knowledge of the use of computer and indirectly helping improve the quality of free, online services.

\section{COMPENSATION}


Participants will be compensated for their time with a \$5 Amazon gift card.

\section{CONFIDENTIALITY}

All data used for scheduling from the recruitment survey (your name, phone number, email, and available times) is securely password protected and will be completely deleted upon completion of this study.

All data collected during the study and used for analysis and possible publication (riskattitude assessment results, gender, and the amount of information provided for each version of the registration) will be associated with a participant number and not tied to any of your personally identifiable information (name, phone, email) from the recruitment survey.

\section{PARTICIPANT RIGHTS.}

Your participation in this study is completely voluntary. You can refuse to participate in the entire study or any part of the study without any negative effect on your relations with San Jose State University. You also have the right to skip any question you do not wish to answer. This consent form is not a contract. It is a written explanation of what will happen during the study if you decide to participate. You will not waive any rights if you choose not to participate, and there is no penalty for stopping your participation in the study.

\section{QUESTIONS OR PROBLEMS}

You are encouraged to ask questions at any time during this study.

- For further information about the study, please contact Nathan Cook at natecook@me.com.

- Complaints about the research may be presented to Dr. Louis E. Freund at louis.freund@sjsu.edu.

- For questions about participants' rights or if you feel you have been harmed in any way by your participation in this study, please contact Dr. Pamela Stacks, Associate Vice President of Graduate Studies and Research, San Jose State University, at 408924-2427.

\section{SIGNATURES}

Your signature indicates that you voluntarily agree to be a part of the study, that the details of the study have been explained to you, that you have been given time to read this document, and that your questions have been answered. You will receive a copy of this consent form for your records.

\section{Participant Signature}




\section{Researcher Statement}

I certify that the participant has been given adequate time to learn about the study and ask questions. It is my opinion that the participant understands his/her rights and the purpose, risks, benefits, and procedures of the research and has voluntarily agreed to participate.

Signature of Person Obtaining Informed Consent

Date 


\section{Appendix D. Risk Attitudes Profiler}

Located at: http://www.humanmetrics.com/rot/rotqd.asp

\section{HUMANMETRICS}

\section{Risk Attitudes Profiler ${ }^{\mathrm{TM}}$ \\ Demo}

This demo is a real risk attitudes test but many features available in RAP test are omitted here.

Please choose one or two options (but not more) when answering the questions in the questionnaire. You can return to a certain question again and check or uncheck needed answers. If you are not sure how to answer then your decision should be based on your most frequent action/feeling in the given situation. It is possible to skip a question if it does not apply to you, but you must answer not less than 19 questions to get a reliable result.

1. When starting a new undertaking you

are likely to doubt its success

weigh the pros and cons well beforehand and consult with experienced people

rely on luck and ignore possible failures

$\square$ are confident of success and sure you will overcome any obstacles

need the guidance of an authoritative person

feel it is worth taking the risk as you will be able to extricate yourself, regardless

are sure that it will be of benefit to mankind

2. In your business/professional activities you

do not usually have competition

take competition into account and look for ways to prevent or reduce it

battle against your competitors

$\square$ are prepared to fight against your competitors by any means necessary and are confident of your victory

are inclined to avoid competition

are keen on competitive struggle

feel ready to eliminate competitors for the common good

3. When driving a car you

always obey traffic laws and avoid dangerous situations

generally always obey traffic laws but if you break the laws you never enter into an argument with the police

react calmly when fined

are ready to break the laws if you don't expect to be fined

generally always obey traffic laws and drive carefully

often break the laws, exceed the speed limit while overtaking

try to obey the laws as far as they do not hinder your purposes but if otherwise you ignore the laws

4. When faced with the opinion of the majority

you're usually in agreement with it

if it differs from your opinion, then you adhere to yours 
if it differs from your opinion, you express it and retain your own views

if it differs from yours, it irritates you since you believe that your opinion is the only right one

if it differs from your opinion, you dare not uphold yours

it doesn't matter to you

you do your utmost to have it on your side, making all others change their mind

5 . When pursuing your goal, you

never infringe the law

don't infringe the law explicitly but exploit its loopholes if necessary

sometimes infringe the law in minor matters, and think nothing of it

sometimes infringe the law if the risk of discovery is small

may infringe the law if you see a number of others doing so

are likely to violate the law if there is a chance of escaping detection

are ready to use almost any means since you think that a great aim justifies any means

6. If duels were permitted, you would

try to avoid them if possible, but if challenged, you wouldn't back out

avoid them at all costs

$\square$ prefer to resolve conflicts in court

accept a challenge but would settle for reconciliation as well

prefer to resolve conflicts by duelling and not in court

always be determined to accept the challenge

ignore the challenge in order to not allow fate to defeat your purpose

7. In games of chance, you

$\square$ don't play

if playing, gamble for low stakes

may play but never beyond the limit of your solvency

play for high stakes, sometimes beyond your solvency

generally don't play since you hate to lose

when playing, sometimes stake your all

don't play on principle

8. You have a preference for people who

you believe are trustworthy

are from your network, or someone you know

are competent

$\square$ are determined and energetic

$\square$ are committed to you and implicitly obedient

are courageous and fond of risks

believe in your ideas

9. In social settings you

join in with what's going on

talk to people who seem to be interesting

are the life and soul of the party

want to be respected and acknowledged as having the right side in arguments

listen to what is being said but do not have enough courage fo join the conversation

often seek adventure

push your ideas 
Pisk-taling assesement teat

11/30/14, 3:50 PM

10. When making a decision, you

usually hesitate a great deal

$\square$ decide after assessing the prospect of success

base your decision more on luck than on thorough reckoning

entertain no doubt about your rightness

tend to postpone it

decide impulsively, relying only on fate and luck

believe firmly in your rightness

11. The anticipation of forthcoming events, whether favorable or unfavorable

worries you but you hope for the best

makes you think over your actions after a bad turn of events

puts you into pleasurable anticipation, leaving no room for the bad

makes you cautious, but you believe you will cope with any turn of events

$\square$ makes you anxious, you expect the worst

excites you, stimulates your energy

mobilizes but doesn't scare you

12. In matters of dress you

dislike extravagant styles, and try not to stand out

prefer an elegant and "quiet" style

$\square$ choose a striking or overtly casual style

$\square$ choose quality, durable goods

$\square$ dress like the others

$\square$ choose a loud, sometimes eccentric style

are content with what you have, paying little attention to the latest fashion

13. As a rule, you enter into intimate relations

casually, without commitment or if you are prepared for marriage

$\checkmark$ with partners whose cultural, social and intellectual level is not lower than yours

if you are seized by strong feelings

$\square$ with partners who recognize your superiority

$\square$ with your soul mate

easily, not looking far ahead

$\checkmark$ when your partners are your companions in some mutual activity

14. When your rights are infringed, you

are likely to be reconciled to it

act the same way as the majority of people around you

will enter into fierce conflict

try to avoid such situations

$\square$ assert your rights whatever the cost

will defend them

$\square$ will uncompromisingly assert them for the sake of common justice

15. When it comes to conflicts, you

manage to avoid them

seldom find yourself involved but if so, act defensively

often get involved, through your own initiative

at times, unexpectedly find yourself involved but never stay involved for long 
often get involved - those around you are to be blamed for that

try to settle it when you enter into one

you go in to crush the enemy

16. In life, you are most concerned about

your professional competence

stable income and job security

quickly moving forward in your endeavours

being successful in your endeavours

your prestige in society

being pleased with yourself and your status

destiny of mankind

17. You prefer to be engaged in something that

gives you moral satisfaction first and foremost

improves your living standard

arouses keen excitement and passion in you

allows you to enjoy your life

enhances your prestige

allows you to live a purposeful life

is very important to the whole of mankind

18. Opponents

are the ones to whom you frequently give in

are the ones you avoid

are the ones you try to destroy

constantly get in your way

are the ones you enter into a fight with

activate you

are people with whom you can compromise if necessary

19. If you have a fairly prosperous life, you

$\square$ are not prepared to risk your current assets while knowing you could have gained more

don't want to make any changes

direct your activity to improving the life of others

are ready to take risks for greater success

feel you could have gained more but were unlucky

sometimes change it drastically for no particular reason

are satisfied but work continuously to improve it

20. When you undertake actions

you are often not sure if they are right

you feel more confident when others approve of them

they are for everybody's good

$\square$ you are sure of their rightness even if others regard them as wrong actions

the warnings of others strengthen your determination to go your own way

they sometimes involve risks, so as to test your abilities, courage and luck

you rely more on your own opinion than on the opinion of others

21. In routine life events

sometimes you want to stay completely alone 
Pisk-taking asseesment teat

$11 / 30 / 14,3: 50 \mathrm{PM}$

it's difficult to you to stay alone

you sometimes wish to go somewhere far away

you need radical changes in your everyday life

people sometimes irritate you

you crave strong excitement and thrils

you are continually engaged in some important task

22. When making investments you prefer to

put your money into no risk but relatively low interest, relatively long-term, programs

put your money into programs recommended by a financial advisor, with sound interest but low to medium risk

invest into what you believe will grow substantially within 1-2 years

invest in rapidly growing companies/markets. Sometimes you might also donate your money to a charity fund.

invest substantial sums of money in reputable enterprises or enterprises to which you give your personal credence

put all of your assets in, if you feel it will yield quick and significant returns

invest in funds which are aimed at promoting the development of mankind and in which you can take part 


\title{
Appendix E. List of Friends
}

\author{
Julie Spoon \\ Jeremy Knife \\ James Fork \\ Katrina Glass
}




\title{
Appendix F. No-Mechanic Design
}

\section{Join Connection+}

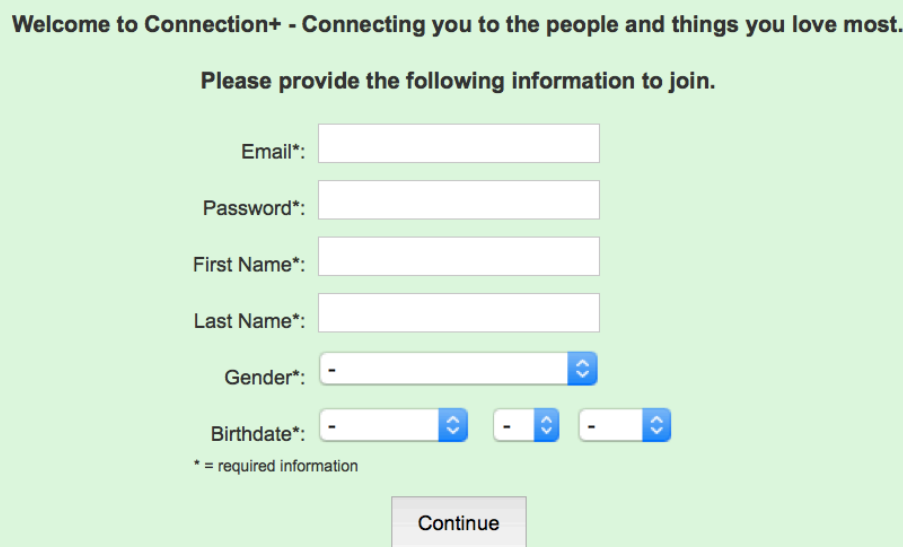

\section{Import Contacts}

\author{
By providing Connection+ with access to your email account's contacts list, we can find \\ even more people who you may know to easily connect you to them on Connection+ \\ Your email: \\ Import Contacts




\section{Follow Friends}

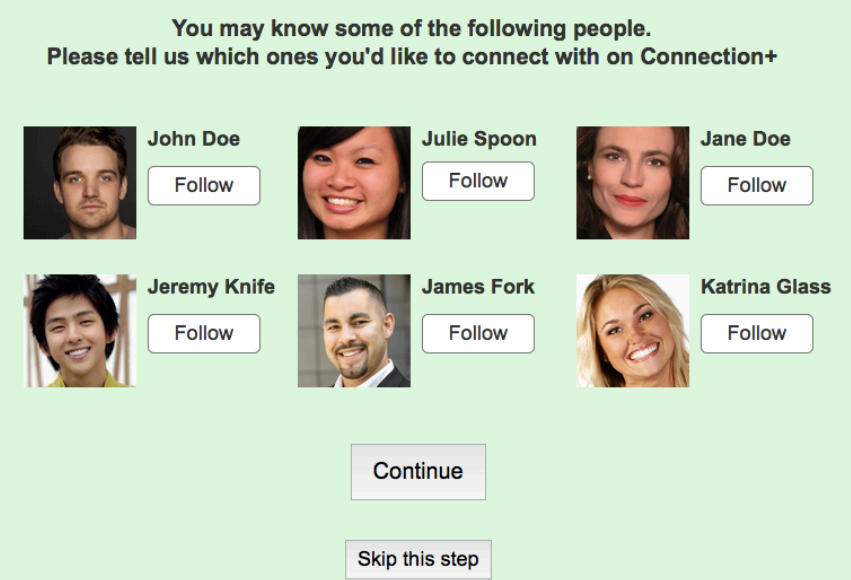

\section{Follow Interests}

Tell us which of the following topics you are interested in and we'll show you related content.

$\square$ Travel

TV Shows

Education

Photography

DIY \& Crafts

Spirituality

Technology
Sports

Nature

Parenting \& Kids

Art \& Design

$\square$ Science

$\square$ Literature

History \& Museums
Music

Movies

Business \& Finance

Politics

Food \& Drink

Health \& Fitness

Home \& Garden
News

Games

Shopping

Fashion \& Beauty

Auto

Weddings

Animals

Continue

Skip this step 


\section{More About You}

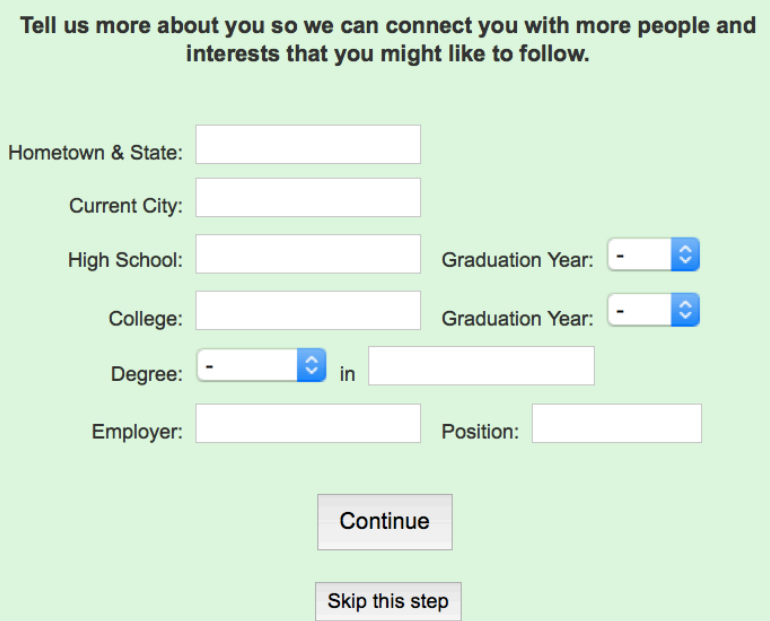

Thank you for Registering! 


\section{Appendix G. Praise-Mechanic Design}

\section{Join Connection+}

Welcome to Connection+ - Connecting you to the people and things you love most.

Please provide the following information to join.

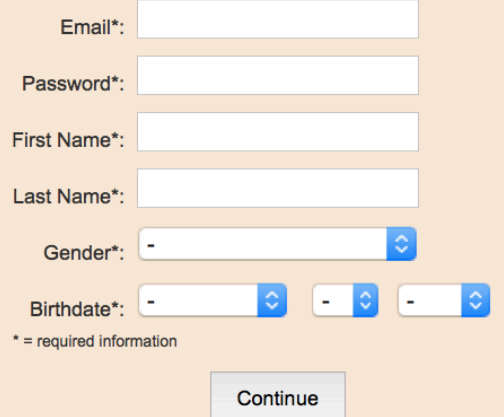

You have the same birthday as Einstein and Madonna! I bet you're just as awesome!

\section{Import Contacts}

By providing Connection+ with access to your email account's contacts list, we can find

even more people who you may know to easily connect you to them on Connection+

Your email:

Import Contacts

Skip this step 
If participants skipped contact import:

I bet you're very popular and have a ton of friends!

\section{Follow Friends}

You may know some of the following people.

Please tell us which ones you'd like to connect with on Connection+

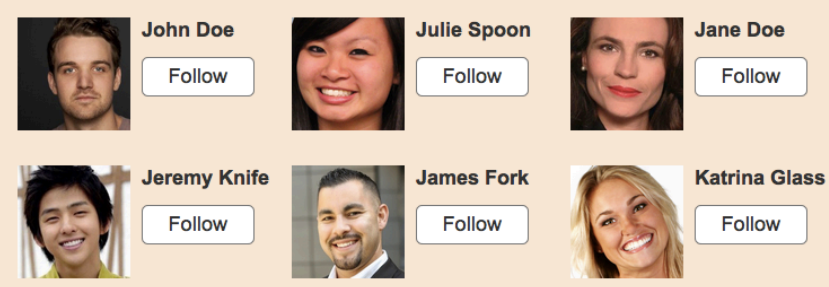

Continue

Skip this step

If participants imported contacts:

Wow, you know a lot of people! You must be really popular!

\section{Follow Friends}

We found the following people from your contact list. Please tell us which ones you'd like to conntect with on Connection+

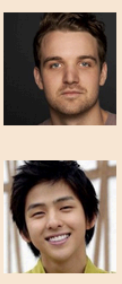

John Doe

Follow

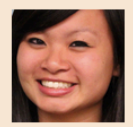

Julie Spoon

\section{Follow}

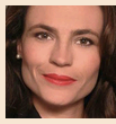

Jane Doe

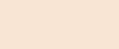

Jeremy Knife

Follow

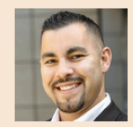

James Fork

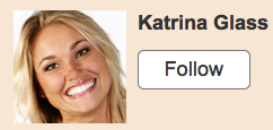

Continue

Skip this step 
If participants skipped adding friends:

Looks like you march to the beat of your own drum. You must be so cool!

\section{Follow Interests}

Tell us which of the following topics you are interested in and we'll show you related content.

$\square$ Travel

TV Shows

Education

Photography

DIY \& Crafts

Spirituality

Technology
Sports

Nature

Parenting \& Kids

Art \& Design

Science

Literature

History \& Museums
Music

Movies

Business \& Finance

Politics

Food \& Drink

Health \& Fitness

Home \& Garden

Continue

If participants added friends:

Your friends are very interesting people!

\section{Follow Interests}

Tell us which of the following topics you are interested in and we'll show you related content.

Travel
TV Shows
Education
Photography
Spirituality Crafts
Technology

$\square$ Sports

$\square$ Nature

Parenting \& Kids

Art \& Design

Science

Literature

History \& Museums
Music

Movies

Business \& Finance

Politics

Food \& Drink

Health \& Fitness

Home \& Garden
News

Games

Shopping

Fashion \& Beauty

Auto

Weddings

Animals

Continue

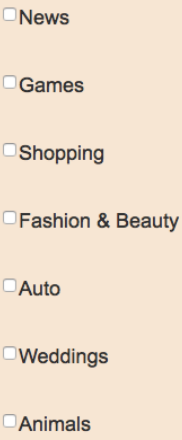

Skip this step 
If participants skipped interest selection:

You sound like a unique individual!

\section{More About You}

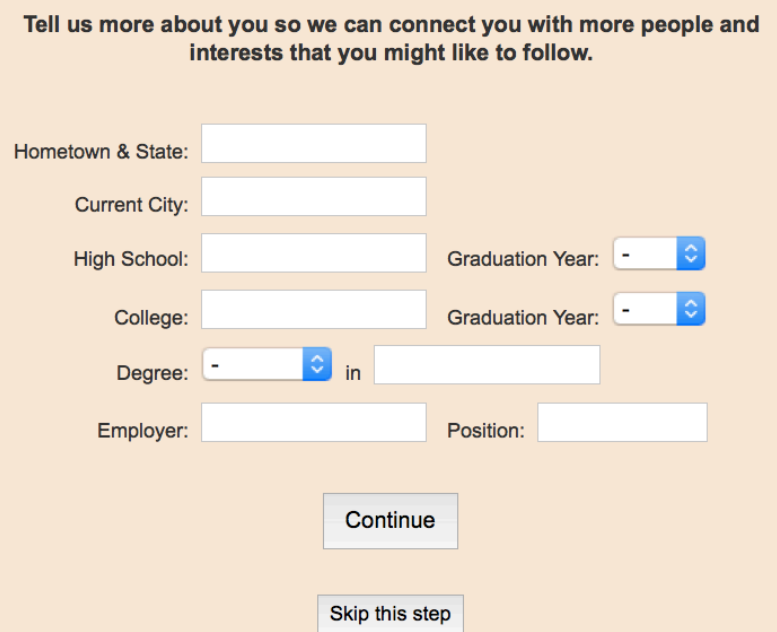

If participants selected interests:

A lot of successful people have similar interests as you!

\section{More About You}

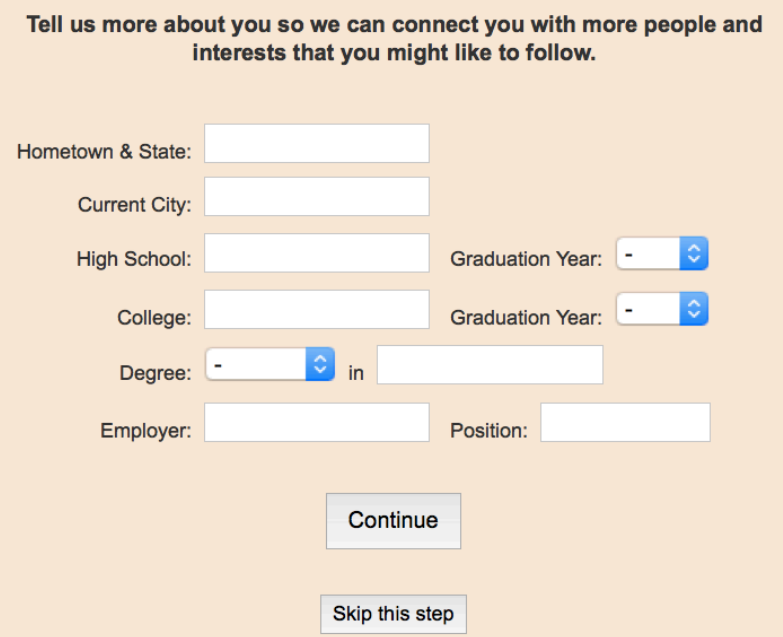




\section{Thank you for Registering!}




\section{Appendix H. Social-Pressure-Mechanic Design}

\section{Join Connection+}

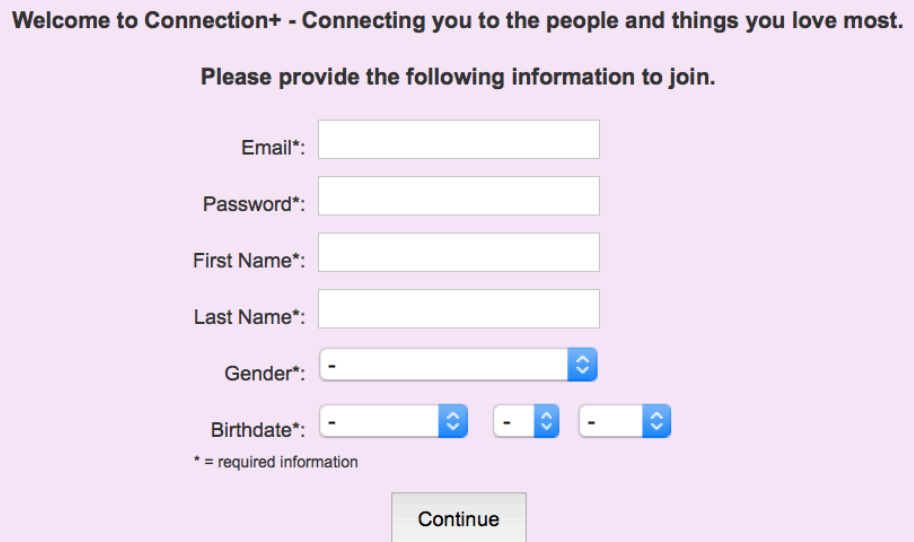

Import Contacts

By providing Connection+ with access to your email account's contacts list, we can find even more people who you may know to easily connect you to them on Connection+

$92 \%$ of people upload their contacts!

Your email:

Import Contacts 
If participants skipped contact import:

\section{Follow Friends}

You may know some of the following people. Please tell us which ones you'd like to connect with on Connection+

$\mathbf{9 8 \%}$ of people on Connection+ follow at least 3 friends

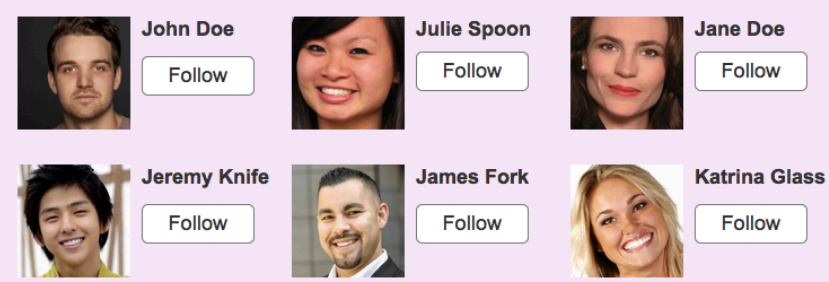

Continue

Skip this step

If participants imported contacts:

\section{Follow Friends}

We found the following people from your contact list.

Please tell us which ones you'd like to conntect with on Connection+

$98 \%$ of your contacts on Connection+ follow at least 3 friends

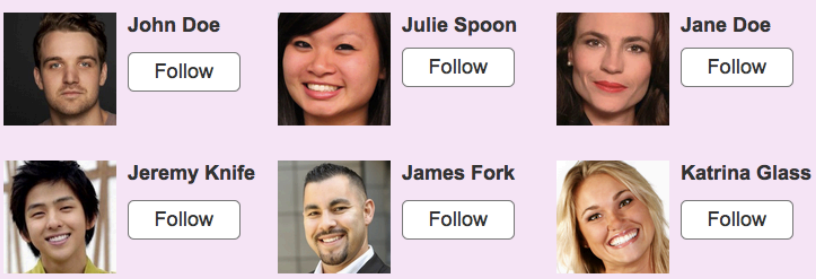

Continue

Skip this step 
If participants skipped adding friend:

\section{Follow Interests}

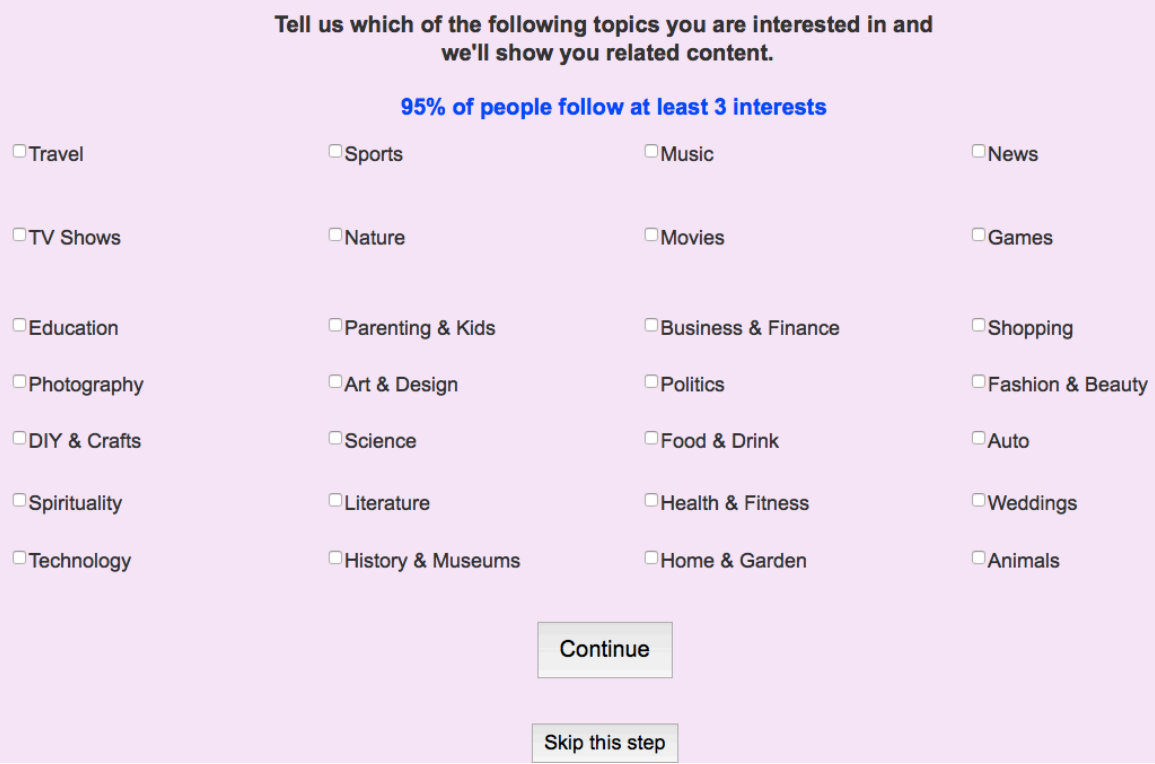

If participants added friends:

\section{Follow Interests}

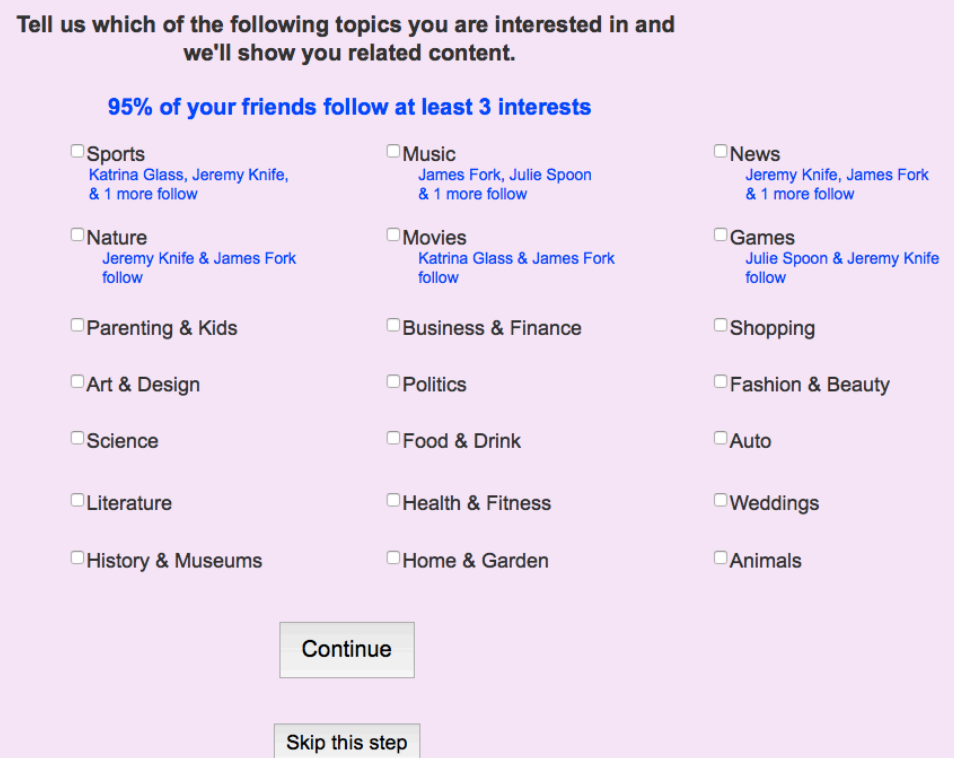


If participant skipped interest selection:

\section{More About You}

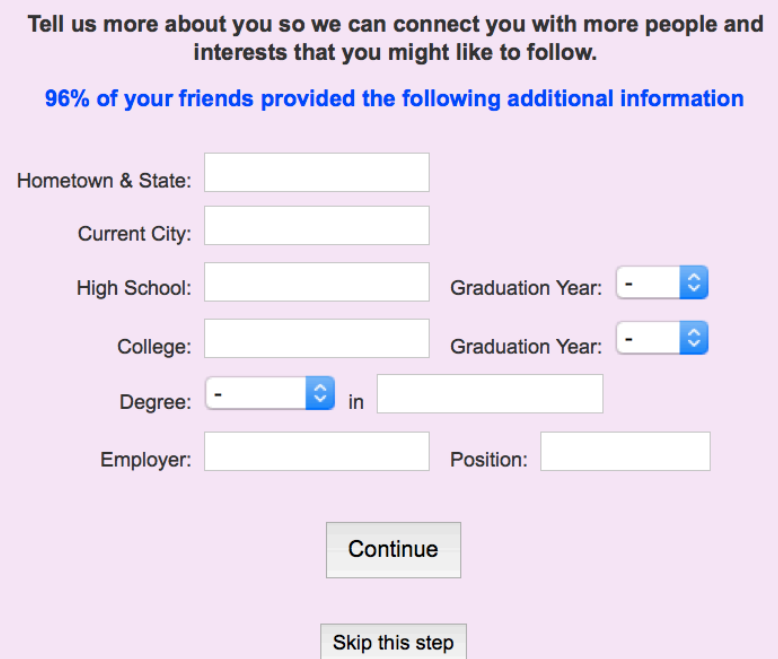

If participant selected interests:

\section{More About You}

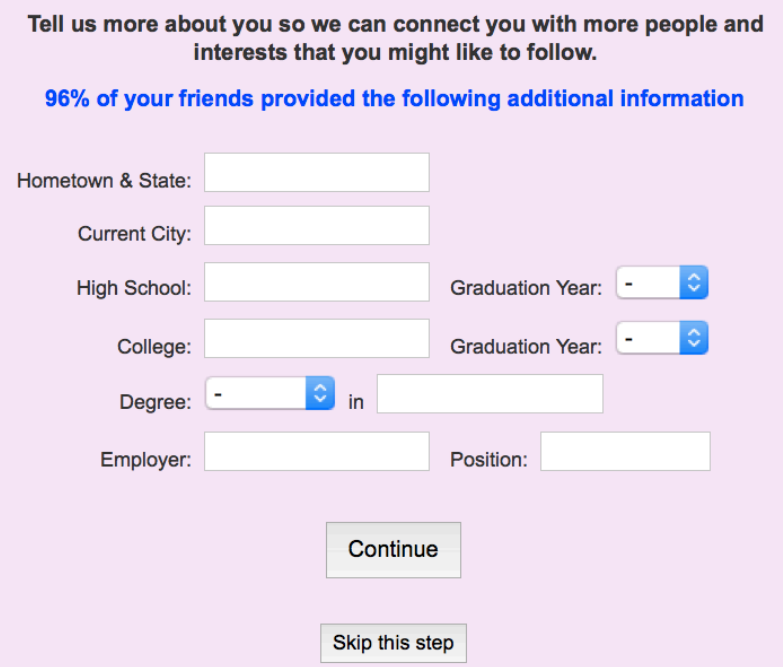




\section{Thank you for Registering!}




\title{
Appendix I. Both-Mechanic Design
}

\section{Join Connection+}

Welcome to Connection+ - Connecting you to the people and things you love most.

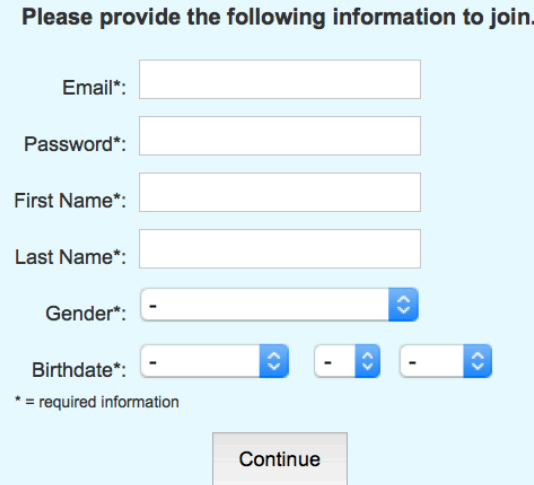

You have the same birthday as Einstein and Madonna! I bet you're just as awesome!

\section{Import Contacts}

\author{
By providing Connection+ with access to your email account's contacts list, we can find \\ even more people who you may know to easily connect you to them on Connection+ \\ $92 \%$ of people upload their contacts! \\ Your email: \\ Import Contacts \\ Skip this step
}


If participants skipped contact import:

I bet you're very popular and have a ton of friends!

\section{Follow Friends}

You may know some of the following people. Please tell us which ones you'd like to connect with on Connection+

$98 \%$ of people on Connection+ follow at least 3 friends

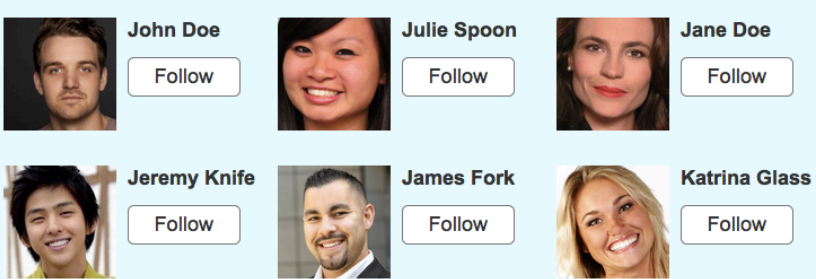

Continue

Skip this step

If participants imported contacts:

Wow, you know a lot of people! You must be really popular!

\section{Follow Friends}

We found the following people from your contact list. Please tell us which ones you'd like to conntect with on Connection+ $98 \%$ of your contacts on Connection+ follow at least 3 friends

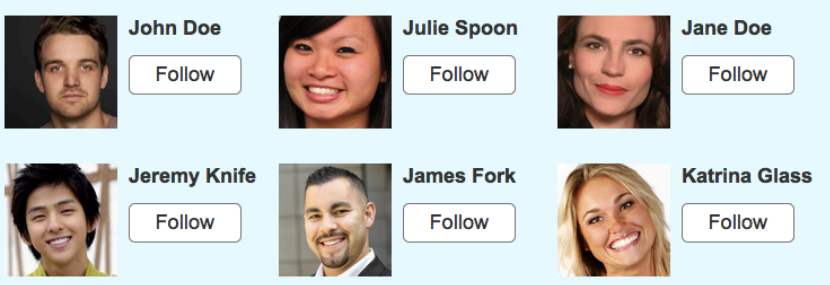

Continue 
If participants skipped adding friend:

Looks like you march to the beat of your own drum. You must be so cool!

\section{Follow Interests}

Tell us which of the following topics you are interested in and we'll show you related content.

$95 \%$ of people follow at least 3 interests

$\square$ Trave

$\square$ TV Shows

Education

Photography

DIY \& Crafts

Spirituality

Technology
Sports

Nature

Parenting \& Kids

Art \& Design

$\square$ Science

$\square$ Literature

$\square$ History \& Museums
Music

$\square$ Movies

Business \& Finance

Politics

Food \& Drink

Health \& Fitness

Home \& Garden

Continue

Skip this step

If participants added friends:

Your friends are very interesting people!

\section{Follow Interests}

Tell us which of the following topics you are interested in and we'll show you related content.

$95 \%$ of your friends follow at least 3 interests

Travel
Julie Spoon, Jeremy Knife,
\& 2 more follow
TV Shows
Katrina Glass \& Julie Spoon
follow
Education
Photography
DIY \& Crafts
Spirituality
Technology

$\square$ Sports

Katrina Glass, Jeremy Knife,

\& 1 more follow

$\square$ Nature

Jeremy Knife \& James Fork

Parenting \& Kids

Art \& Design

Science

$\square$ Literature

History \& Museums

Music
James Fork, Julie Spoon
\& 1 more follow
Movies
Katrina Glass \& James Fork
follow
Business \& Finance
Politics
Food \& Drink
Health \& Fitness
Home \& Garden

Home \& Garden

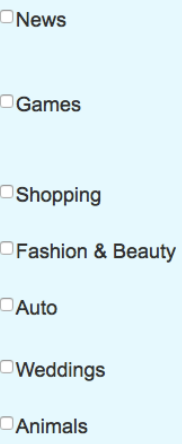

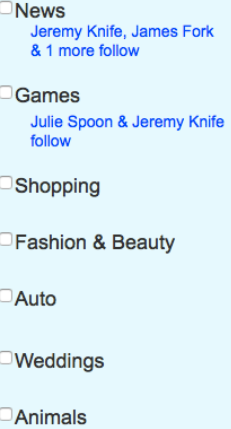


If participant skipped interest selection:

You sound like a unique individual!

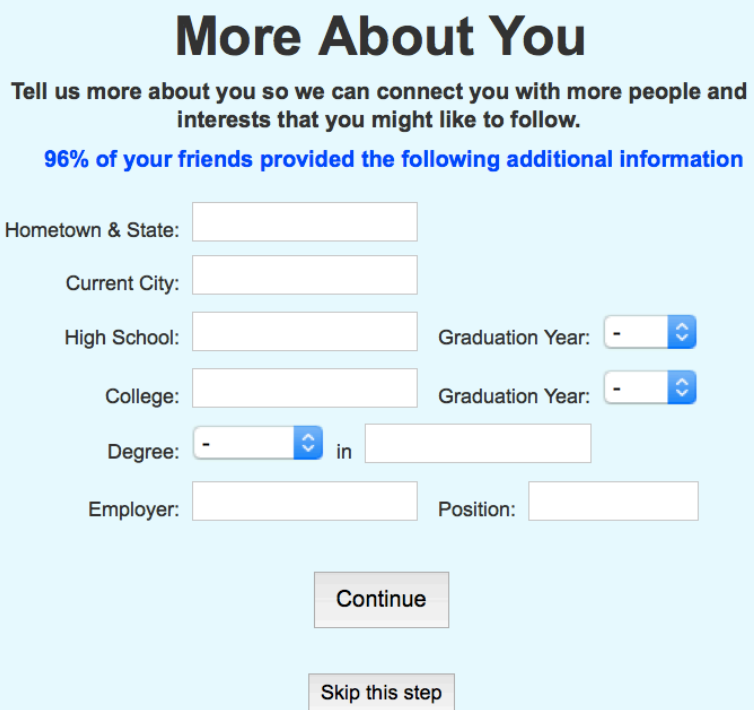

If participants selected interests:

A lot of successful people have similar interests as you!

\section{More About You}

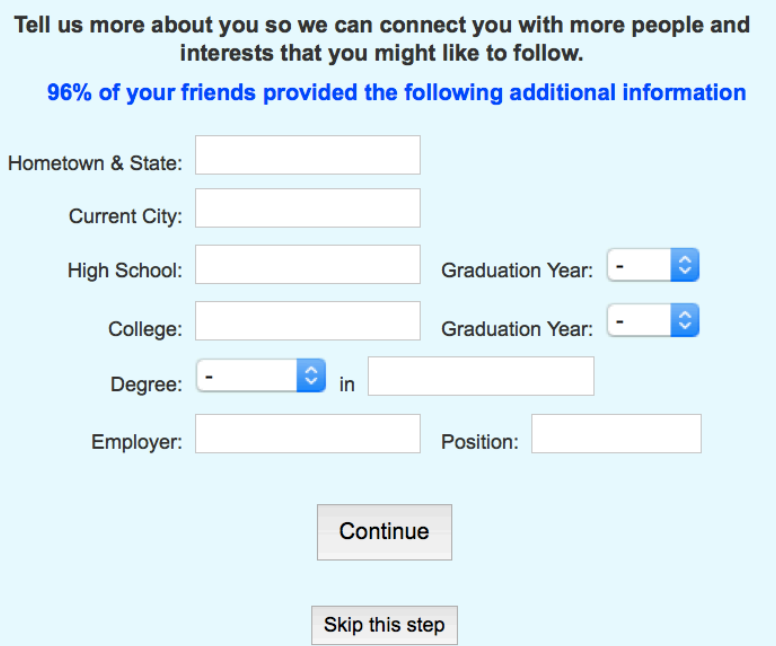




\section{Thank you for Registering!}




\section{Appendix J. Persuasiveness Question}

[This question will be asked verbally and the participant's verbal response will be written down by the researcher after the participant experiences each registration. The question will be worded as below, and a piece of paper with the question and its scale, exactly like the below text will be presented to the participants]

To what extent did this design dissuade or persuade you to provide information and complete the registration?

1. Completely dissuaded me

2. Very much dissuaded me

3. Somewhat dissuaded me

4. Neither dissuaded or persuaded

5. Somewhat persuaded me

6. Very much persuaded me

7. Completely persuaded me

Why? 


\section{Appendix K. Counterbalancing}

None, Praise, Social, Both

None, Praise, Both, Social

None, Social, Praise, Both

None, Social, Both, Praise

None, Both, Praise, Social

None, Both, Social, Praise

Praise, None, Social, Both

Praise, None, Both, Social

Praise, Social, None, Both

Praise, Social, Both, None

Praise, Both, Social, None

Praise, Both, None, Social

Social, None, Praise, Both

Social, None, Both, Praise

Social, Praise, Both, None

Social, Praise, None, Both

Social, Both, Praise, None

Social, Both, None, Praise

Both, Praise, Social, None

Both, Praise, None, Social

Both, Social, Praise, None

Both, Social, None, Praise

Both, None, Praise, Social

Both, None, Social Praise 


\section{Appendix L. Data Tracing Sheet}

\section{Participant \#:}

Gender (circle): F / M

Risk Attitude (circle): Low / Moderate / High

Design 1:

Type (circle): None / Praise / Social Comparison / Both

Number of data points supplied [tally here]:

Completed registration (circle): Y / N

If no, where stopped and why?

Self-reported persuasiveness:

Why?

Design 2:

Type (circle): None / Praise / Social Comparison / Both

Number of data points supplied [tally here]:

Completed registration (circle): Y / N

If no, where stopped and why?

Self-reported persuasiveness:

Why? 
Design 3:

Type (circle): None / Praise / Social Comparison / Both

Number of data points supplied [tally here]:

Completed registration (circle): Y / N

If no, where stopped and why?

Self-reported persuasiveness:

Why?

Design 4:

Type (circle): None / Praise / Social Comparison / Both

Number of data points supplied [tally here]:

Completed registration (circle): Y / N

If no, where stopped and why?

Self-reported persuasiveness:

Why?

End of Study:

Self-reported most persuasive design (circle):

None / Praise / Social Comparison / Both

Why? 